\title{
EL TEATRO EN EL CONTEXTO URBANO DE COLONIA PATRICIA (CÓRDOBA): AMBIENTE EPIGRÁFICO, EVERGETAS Y CULTO IMPERIAL *
}

\author{
POR
}

\author{
ÁNGEL VENTURA VILLANUEVA \\ Seminario de Arqueología de la Universidad de Córdoba
}

\begin{abstract}
RESUMEN
En 1994 fueron descubiertos los vestigios del teatro romano de la Colonia Patricia, bajo el edificio del Museo Arqueológico Provincial de Córdoba, en el entorno de la actual Plaza de Jerónimo Páez. Dicha localización permite ahora contextualizar los hallazgos epigráficos de esta zona, incrementando así nuestro conocimiento histórico respecto al edificio de espectáculos y respecto a la sociedad que lo construyó y utilizó en época augustea.
\end{abstract}

\section{SUMMARY}

In 1994 the remains of the Roman theater of Colonia Patricia (Córdoba) were discovered under the building of the Museo Arqueológico Provincial. This precise localisation allows us to re-examine the epigraphical discoveries of the neighbourhood into their original context and to increase our knowledge about the monument and the society that erected and used it in the Augustan era.

\section{INTRODUCCIÓN}

Es objetivo del presente estudio ejemplificar la estrecha relación existente entre Epigrafía y Arqueología. Intentaremos profundizar en la condición de auxiliaridad recíproca de ambas disciplinas y aplicar el método adecuado para, con las informaciones obtenidas desde una y otra, lograr un más ajustado conocimiento histórico.

Este posicionamiento teórico, considerado hoy día natural, no se fraguó hasta la segunda mitad del presente siglo. Hasta entonces, el único valor otorgado a las inscripciones se centraba en su contenido textual. La elaboración de los monumentales corpora a finales del siglo XIX vino a satisfacer las necesidades de las corrientes historicistas y positivistas, imperantes por entonces y convencidas de que el progreso en el conocimiento histórico sólo

* Todas las ilustraciones son obra del autor, a excepción de las figs. 1-2, realizadas en colaboración con J. F. Murillo, R. Hidalgo, C. Márquez y J. R. Carrillo; la fig. 8, cortesía de P. Connolly y la fig. 9 , cortesía de A. U. Stylow. era posible a través de la acumulación de nuevos datos documentales.

La reacción a tales planteamientos comenzó en los años 50 desde dos campos muy distintos. Por un lado, el arqueólogo español J.M. Navascués abogaría por dotar de contenido propio a la ciencia epigráfica, emancipándola de la Filología, a través del estudio de la materialidad misma de las inscripciones, aspecto absolutamente descuidado hasta entonces ${ }^{1}$. Por otro, la nueva escuela francesa de Paleografía, liderada por J. Mallon, resaltaría la importancia de los aspectos formales de la escritu$\mathrm{ra}^{2}$. Algunos años más tarde, G. Susini sistematizaría y ampliaría tales planteamientos, acuñando dos conceptos fundamentales; a saber, los de «arqueología de la epigrafía» y «ambiente o paisaje epigráfico» ${ }^{3}$. El primero designa el estudio de los procesos de producción del epígrafe, desde la extracción de la materia prima en la cantera hasta su disposición definitiva en el lugar al que iba destinado, pasando por la elaboración de los soportes y la redacción e inscripción del texto. El segundo pretende llamar la atención sobre la necesidad de contextualizar las inscripciones, pues era en el ambiente original de colocación donde éstas alcanzaban pleno significado para sus contemporáneos y, por ende, el lugar donde ofrecen una información más completa al investigador. Se trata, pues, de analizar no sólo lo que el texto dice, sino también el cómo, por qué, desde dónde y para quién o quiénes iba destinado su mensaje. Y la disciplina capaz de reconstruir tales ambientes originales, las más de las veces desaparecidos o maltrechos, es la Arqueología.

Los estudios de «ambiente epigráfico» presentan una doble vía de investigación. De un lado, el análisis de los programas epigráficos propios de espacios, edificios o monumentos urbanos concretos.

\footnotetext{
1 Navascués, J.M., El concepto de epigrafía. Consideraciones sobre la necesidad de su ampliación, Madrid 1953.

2 Mallon, J., Paléographie romaine, Madrid 1952. Idem, De l'écriture, Paris 1982.

3 Susini, G., Il lapicida romano, Roma 1969, 78-83. Idem, Epigrafia romana, Roma 1982, 16-19.
} 
Problemas arqueológicos tales como la datación, funcionalidad, ornamentación, evolución, identidad del comitente o patrocinador de tales obras e intencionalidad de su acto evergético, pueden solucionarse satisfactoriamente analizando la evidencia epigráfica recuperada en ellos, no de forma aislada (inscripción por inscripción), sino en su conjunto, entendido éste como un auténtico programa de autorrepresentación social ante los contemporáneos y la posteridad ${ }^{4}$. De otro lado, una vez identificadas las pautas de disposición original de las diferentes inscripciones que componían tales programas en aquellos edificios satisfactoriamente conservados o investigados, tal modelo sirve para identificar dichos ambientes, o localizar tales edificios, en otras ciudades, a partir de la concentración de determinados hallazgos epigráficos casuales.

Vamos a utilizar esta doble vía de investigación con un caso concreto: el ambiente epigráfico del teatro romano de Córdoba, puesto que el reciente conocimiento de su ubicación en la trama urbana de la ciudad permite dotar de nuevo significado a las inscripciones recuperadas en su entorno y, por esa misma razón, incrementar nuestro conocimiento histórico sobre el edificio.

\section{EL CONTEXTO URBANÍSTICO DE LA COLONIA PATRICIA AUGUSTEA}

El principado de Augusto (30 a.C.-14 d.C.) representa para Corduba un momento clave, pues durante este período se configura la imagen urbana que perdurará a lo largo de toda la Antigüedad. El proceso de transformación urbanística, así como los principales programas edilicios y ornamentales que lo componen, han sido definidos por varios autores en fechas muy recientes ${ }^{5}$. Nuestra labor debe, por lo tanto, reducirse a ofrecer una síntesis de lo hasta ahora conocido y publicado; aportando, eso sí algunas puntualizaciones.

\footnotetext{
4 Alföldy, G., Augusto e le iscrizioni: tradizione ed innovazione. La nascitá dell'epigrafia imperiale, Scienze dell'Antichità 5, 1991, 573-575.

5 León, P. (ed.), Colonia Patricia Corduba, una reflexión arqueológica. Coloquio internacional, Córdoba 1993. Sevilla 1996. Ventura, A., El abastecimiento de agua a la Córdoba romana II: acueductos, ciclo de distribción y urbanismo, Córdoba, 1996, 140-144. Ventura, A., León, P. y Márquez, C. Roman Córdoba in the light of recent archeological reseach, The archaeology of early Roman Baetica. Ed. S. Keay, JRA Suppl. 29, Portsmouth 1998, 87-107. Márquez, C., La decoración arquitectónica de Colonia Patricia. Una aproximación a la arquitectura y al urbanismo de la Córdoba romana, Córdoba 1998.
}

Tras la destrucción sufrida por Corduba durante la guerra de Munda, no total, pero sí intensa, en el año 45 a.C. ' , es probable que César ordenara el establecimiento de una colonia romana «de castigo», consecuencia de su actitud ambigua o abiertamente filopompeyana durante el conflicto ${ }^{7}$. Posteriormente, pero con anterioridad al 14 a.C. - tal vez en 25 a.C., coincidiendo con la reorganización administrativa de las provincias de Hispania-, Augusto, heredero y sucesor de César, culminaría tales proyectos deduciendo definitivamente la Colonia Patricia y asentando en ella un contingente de veteranos licenciados del ejército, a lo que aludirían tanto algunas acuñaciones de la ciudad con signa legionarios en los reversos, como la constatación epigráfica de una nueva tribus - Galeria - en la que se inscriben sus ciudadanos ${ }^{8}$. La Colonia Patricia pasa a ser capital de la provincia Baetica y del conventus Cordubensis, afianzando de iure la preeminencia que había ostentado durante la época republicana respecto al resto de ciudades de la provincia ${ }^{9}$.

Estos acontecimientos políticos deben haber jugado un papel fundamental como motor del cambio urbanístico que se documenta arqueológicamente. En efecto, en este período se constata la ampliación del recinto amurallado de la ciudad hacia el Sur, hasta prácticamente la orilla del Guadalquivir, incrementando así su extensión en $36 \mathrm{Ha}$. (superficie total: $78 \mathrm{Ha}$.) Probablemente la ampliación sirviera para acoger a los colonos augusteos (cfr. figs. 1 y 2).

La reciente investigación topográfica permite emprender estudios detallados sobre la red viaria y su modulación. Es posible, de este modo, conocer el modelo teórico de limitatio de parcelas intraurbanas en la ampliación augustea de Córdoba. El trazado del viario parte de la bifurcación del Kardo Maximus republicano en su extremo meridional, en la confluencia de la actual c/ Blanco Belmonte hacia la Plaza de Benavente. Un ramal adopta una dirección NW.-SE., coincidiendo aproximadamente con la c/ Rey Heredia. Esta «diagonalis» segrega un sector intraurbano -el suroriental- destinado a «barrio de espectáculos», reservándose aquí el espacio necesario para la edificación del teatro - que aprovecha el escarpe de la terraza fluvial-y, al sur de él

\footnotetext{
'Bell. Hisp. 34.
}

Canto, A.M., Algo más sobre Marcelo, Corduba y las Colonias Romanas del año 45 a.C., Gerión 15, 1997, 253281.

8 Stylow, A.U., De Corduba a Colonia Patricia. La fundación de la Corduba romana, Colonia Patricia Corduba, una reflexión arqueológica. Ed. León, P., Córdoba 1996, 80-82. ' Cfr. Bell. Hisp. 3.1, Strab. Geog. 3,2,1 y Plin. Nat. Hist. III, 10 


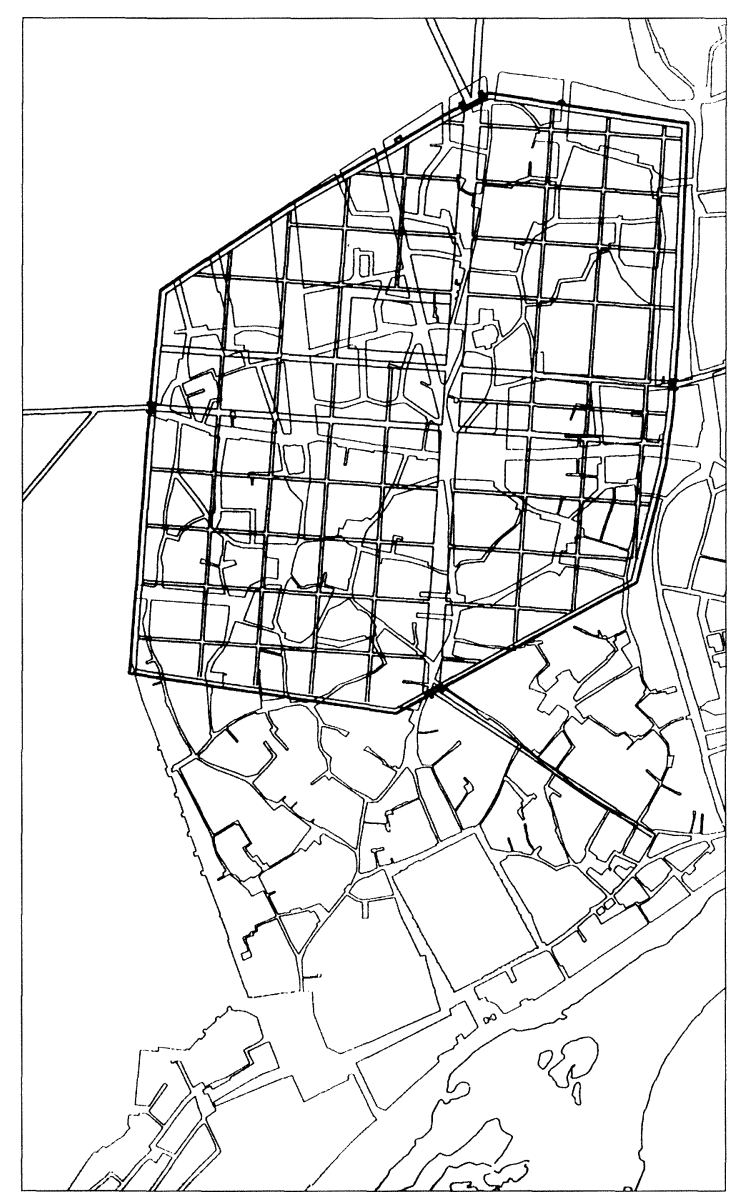

Fig. 1.-Plano de la Corduba republicana, sobre parcelario actual, a escala aprox. 1:15000.

y en eje, el anfiteatro ${ }^{10}$. El segundo ramal del Kardo Maximus, que consideramos principal por encaminarse hacia el puente y la puerta allí ubicada, presenta una orientación diferente a las murallas, pero que ha quedado fosilizada en la nave central de la Mezquita Aljama ${ }^{11}$. Siguiendo esta misma orienta-

${ }^{10}$ La hipótesis de localización del anfiteatro, todavía no confirmada arqueológicamente, en: Ventura, A., La recuperación de la Córdoba romana: los edificios de espectáculos, Ciudades modernas superpuestas a las antiguas. 10 años de investigación, Coloquio Mérida (julio 1996), Badajoz 1997, 33-54.

"La argumentación respecto al trazado del K.M. bajo la nave del mihrab de la Mezquita aljama la ofrecimos en: Ventura, A., et alii, Análisis arqueológico de la Córdoba romana, resultados e hipótesis de la investigación, Colonia Patricia Corduba, una reflexión arqueológica, Ed. León, P. Sevilla 1996, 105-109. Esta propuesta de trazado hace desembocar la calle unos diez metros al Este de la desembocadura del puente romano de piedra sobre el Guadalquivir. Opinamos que dicha desviación nos pone tras la pista de la preexistencia de un puente de madera, anterior al de piedra y desde el que se abordaría la construcción de éste. Algo lógico si pen-

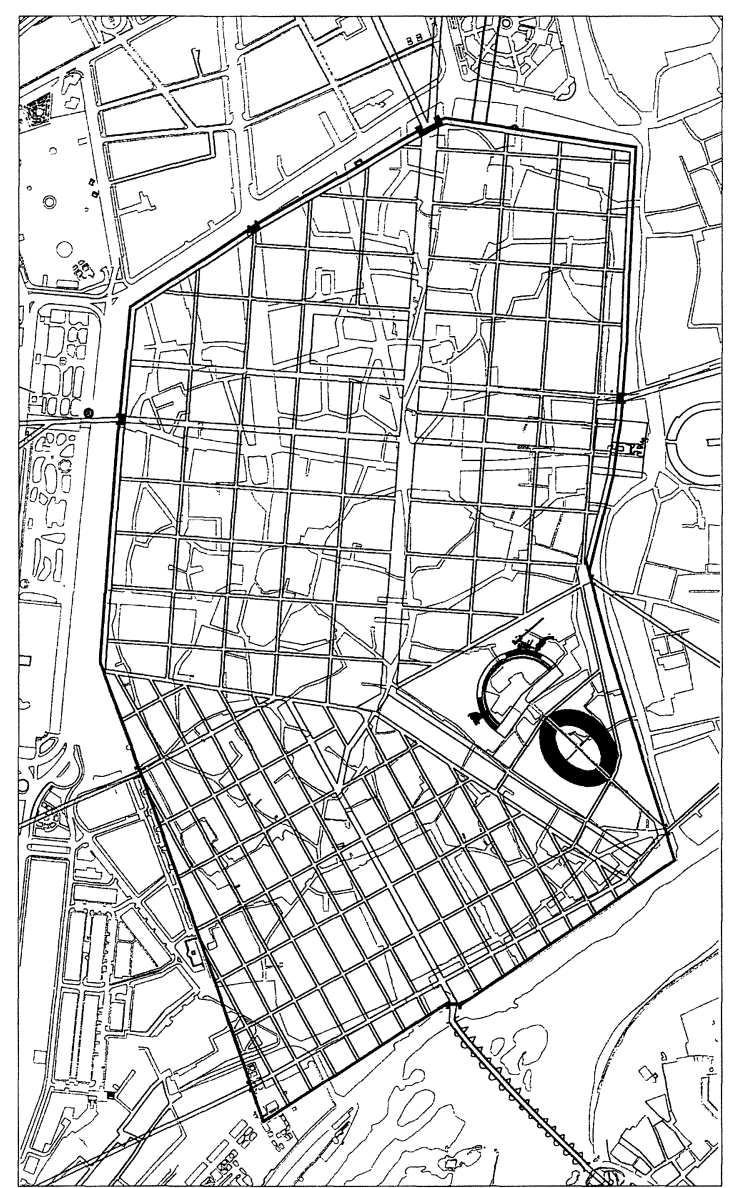

Fig. 2.-Plano de la Colonia Patricia augustea, sobre parcelario actual, a escala aprox. 1:15000.

ción se trazan el resto de kardines, espaciados $35 \mathrm{~m}$ cada uno. Conocemos 5 de ellos, que corresponden, de O. a E., a la actual c/ Torrijos, nave central de la Mezquita, c/ Céspedes, Pórtico Este del Patio de los Naranjos y parcelas orientales de la c/ Caño Quebrado ${ }^{12}$. Peor informados estamos respecto a los

samos que la deductio colonial, y las transformaciones urbanísticas consecuentes, acontece entre los años 45 y 14 a.C., mientras que el puente de piedra se fecha en los años 3-2 a.C., en el marco del acondicionamiento de la Via Augusta documentado por los miliarios: Stylow, A.U., Apuntes sobre el urbanismo de la Corduba romana, Stadtbild und Ideologie. Die Monumentalisierung hispanicher Städte zwischen Republik und Kaiserzeit, Eds. Trillmich, W., Zanker, P., München 1990, 262. Un caso similar se documenta en Mérida: Mateos, P., Reflexiones sobre la trama urbana de Augusta Emerita, Anas 7-8, 1994-95, 237-238.

12 El kardo detectado en la excavación de la calle Caño Quebrado se fecha a comienzos de época imperial: Morena, J.A., Apuntes sobre urbanismo y economía en el sector meridional de la Córdoba Romana. Excavación de urgencia en c/ Caño Quebrado esquina Ronda de Isasa, Boletín de la Real Academia de Córdoba 134, 1999 (e.p.). 
decumani, aunque los conocidos se espacian 70 metros. Tendríamos así insulae de $35 \times 70 \mathrm{~m} \mathrm{(2} \mathrm{ac-}$ tus), aunque cabe la posibilidad de que éstas estuvieran subdivididas por otros decumani no documentados hasta ahora, midiendo entonces $35 \times 35 \mathrm{~m}$ (1 actus). Ambas dimensiones, en todo caso, están documentadas para otras colonias romanas de época triunviral o augustea ${ }^{13}$. Existe además una estrecha relación entre el trazado urbanístico republicano de la ciudad alta y el que se acomete posteriormente en la zona meridional: la prolongación de los kardines de la parte alta sobre la diagonalis- c/ Rey Heredia y su proyección ortogonal sobre otro kardo paralelo a ella (y situado un actus al SW.), determina los puntos desde los que parten los decumani de la ampliación augustea, con módulo 2 actus. Esta limitatio, tan regular y de parcelas reducidas, nos hace sospechar en un reparto viritim vinculado a la deductio de veteranos (fig. 2).

$\mathrm{Al}$ mismo tiempo que se reorganiza su interior, la ciudad se «abre» hacia el exterior, una vez concluidas las guerras civiles (provincia Baetica pacata est, se lee en una inscripción del Foro de Augusto en Roma). Capital administrativa, económica y política de un territorio provincial, es precisamente la calzada que articula este territorio, la Via Augus$t a$, la que vertebra también la ciudad ampliada, pues pasa a ser Decumanus Maximus (c/ Alfonso XIII) y Kardo Maximus (calles San Alvaro, Jesús María y Blanco Belmonte) ${ }^{14}$. Otros indicios de apertura territorial serían la parcelación agraria (centuriatio) con la misma orientación que la documentada para el viario intramuros ${ }^{15}$, la presencia de suntuosos monumentos funerários a lo largo de las calzadas que salen de las puertas úrbicas, o la propia ornamentación de éstas ${ }^{16}$.

Las calles de la ampliación augustea, y también las de la vieja Corduba (zona norte), se dotan en estos momentos de cloacas y se pavimentan ${ }^{17}$. Debe

13 Sommella, P., Italia Antica. L'urbanistica romana, Roma 1988, passim.

14 Ventura, A., Carmona, S., Resultados sucintos de la excavación arqueológica de urgencia en la c/ Blanco Belmonte no 4-6 y Ricardo de Montis 1-8, Córdoba. Sobre el trazado del Cardo Maximo de la Colonia Patricia Corduba, Anales de Arqueología Cordobesa 3, 199-242.

${ }_{15}$ Corzo, R., Topografía y territorio de la Córdoba romana, Colonia Patricia Corduba, una reflexión arqueológica, op. cit. n. 5, 63-75.

16 Destacan los dos «mausoleos» gemelos de planta circular recientemente excavados y puestos en valor en el Paseo de la Victoria, inmediatamente a las afueras de la Puerta de Gallegos (lienzo occidental de la muralla): Murillo, J.F., Carrillo, J.R., Monumento funerario romano de Puerta de Gallegos, Córdoba en tiempos de Séneca, Ed. Vaquerizo, D., Córdoba 1996, 186-189.

17 Ventura, A., op. cit. n. 5, 140-144. repararse en la magnitud de la empresa, a tenor de los kilómetros de conducciones y toneladas de piedra necesarios. Algunas calles, también, se dotan de pórticos sobre las aceras ${ }^{18}$. La red de saneamiento está sin lugar a dudas vinculada a la construcción del primer acueducto con que contó la ciudad: el Aqua Augusta (acueducto de Valdepuentes), de probable financiación imperial ${ }^{19}$. Como también lo están las fuentes públicas en las plazas y calles, que se calculan en un centenar, a juzgar por el caudal transportado por el acueducto ( $30.000 \mathrm{~m}^{3}$ de agua al día). Algunas de estas fuentecillas pétreas, decoradas con mascarones de bronce - effigies aheneas-, fueron donadas por un miembro de la oligarquía local, $L$. Cornelius, con posterioridad al desempeño de las más altas magistraturas ciudadanas ${ }^{20}$.

Las nuevas élites coloniales se «apropian» del espacio público representativo tradicional, de manera similar a lo constatado en Pompeya tras la deductio silana ${ }^{21}$. Así, las recientes excavaciones de las c/ Góngora y Teniente Braulio Laportilla, han permitido comprobar intensas reformas en el viejo foro republicano, que comprenden la pavimentación de la plaza con losas de caliza micrítica gris ${ }^{22}$, la instalación en ella de fuentes públicas, o la renovación de su porticado perimetral. Herramienta fundamental en este proceso de «colonización ideológica» del espacio urbano es la cultura epigráfica. Las élites dejan testimonio escrito, público, monumental y perenne de sus logros; a veces incluso acompañado de su propio retrato. Pedestales y estatuas proliferan en plazas, calles y edificios, las más de las veces dedicadas por el propio cuerpo de ciudadanos al político o benefactor de turno. Especial atención merecen dos aspectos de este incipiente hábito epigráfico, en cierto modo peculiares de la Corduba augustea. De un lado, las dedicaciones realizadas por coloni e incolae mencionados por

18 Hidalgo, R., Nuevos datos sobre el urbanismo de Colonia Patricia Corduba: excavación arqueológica de urgencia en la c/ Ramírez de las Casas-Deza 13, Anales de Arqueología Cordobesa 4, 1993, 91-134.

19 Ventura, A., op. cit. n. 5, 62-63 y 126-132. Idem, El abastecimiento de agua a la Córdoba romana I: el acueducto de Valdepuentes, Córdoba 1993, passim.

${ }_{20}$ Stylow, A.U. (ed.), Corpus Inscriptionum Latinarum vol II, Inscriptiones Hispaniae, editio altera, Fasciculus VII, Conventus Cordubensis. Berlin-New York $=\mathrm{CIL} \mathrm{II}^{2} / 7, \mathrm{n}^{\circ} \mathrm{s}$ 218-219.

${ }_{21}$ Zanker, P., Pompei, Torino 1993, 71-83.

22 Aparicio, L., Ventura, A., Flamen provincial documentado en Córdoba y nuevos datos sobre el Foro de la Colonia Patricia, Anales de Arqueología Cordobesa 7, 1996, 251264. La pavimentación de fora en época augustea se documenta en otras ciudades, comenzando por el Foro Romano: Alföldy, G., Der Obelisk auf dem Petersplatz in Rom, Heidelberg 1990, 72 . 
separado ${ }^{23}$, que a nuestro juicio demuestran el sentimiento de unidad de los colonos augusteos respecto a los habitantes anteriores a la deductio ${ }^{24}$. De otro lado, el empleo de la ostentosa técnica de las litterae aureae - letras de bronce bañadas en oro e incrustadas en soporte pétreo-, propia de los monumentos imperiales o, cuando menos, comunitarios, en monumentos funerarios privados ${ }^{25}$.

También las innovaciones en el campo arquitectónico contribuyeron a transformar el paisaje urbano; en especial, la introducción del mármol como material constructivo programático y la adopción de modelos romanos en el lenguaje decorativo ${ }^{26}$. Algunas piezas, colosales y elaboradas en mármol de Luni-Carrara, ponen tras la pista de monumentos patrocinados directamente por el emperador, propietario de las canteras ${ }^{27}$.

La adhesión comunitaria hacia el nuevo régimen de paz y prosperidad promovido por Augusto se constata no sólo en las élites, sino también en el populus. Las actividades vecinales de culto al emperador afectan incluso a la, digamos, «nomenclatura» urbana, pues es por esta causa por la que se establece una división oficial de la ciudad en distritos o vici, de los que conocemos por el momento dos denominados forensis e Hispanus ${ }^{28}$. También, extramuros, se documenta una barriada o pagus Augustus ${ }^{29}$. Toda esta transformación urbana no es sino la consecuencia de un profundo cambio cultural, en buena medida generalizable a otras ciudades en este momento histórico, pero con las peculiaridades de magnificencia inherentes a una capital provincial y al poder económico de sus élites sociales.

\section{LA EVIDENCIA ARQUEOLÓGICA SOBRE EL TEATRO}

Sin lugar a dudas, el teatro es el monumento más emblemático de la Colonia Patricia augustea. La

\footnotetext{
${ }^{23}$ E.g. CIL II ${ }^{2} / 7, \mathrm{n}^{\circ} 283,311$.

24 Similar constatación en la Pompeya silana: Zanker, P., op. cit. n. 21, 81. Véase también: Rizakis, A.D., Incolae-Paroikoi: populations et communautés dépendantes dans les cités et les colonies romaines de I'orient, Revue des Études Anciennes 100, 1998, 599-617.

25 E.g. CIL II ${ }^{2} / 7, \mathrm{n}^{\circ} 323,720$. Sobre esta técnica de escritura lapidaria y sus implicaciones ideológicas vide Alföldy, G., art. cit n. 4 e Idem, op. cit. n. 22, 68-74.

${ }^{26}$ Márquez, C., Corrientes y materiales en la arquitectura de la Córdoba romana, Anales de Arqueología Cordobesa 6 , 1995, 76-113.

27 Pensabene, P., Classi dirigenti, programmi decorativi, culto imperiale: il caso di Tarraco» en Colonia Patricia Corduba. Una reflexión arqueológica, op. cit. n. 5, 222.

${ }^{28} \mathrm{CIL} \mathrm{II}^{2} / 7, \mathrm{n}^{\circ} 272$ y 273 . Ventura, A., Inscripciones honoríficas, Córdoba en tiempos de Séneca, op. cit. n 16, 74-77.
}

investigación arqueológica sobre sus vestigios se inició en 1994, cuando las excavaciones practicadas en el denominado «Patio Romano» del interior del Museo Arqueológico Provincial (Plaza de Jerónimo Páez), localizaron la cimentación oriental de la fachada curva de la cavea. Posteriores excavaciones durante los años 1995 y 1996 en solares de la c/ Rey Heredia detectaron la misma cimentación en su tramo occidental ${ }^{30}$. Mejor conocido que el edificio en sí resulta su entorno inmediato, compuesto por un complejo de plazas aterrazadas que lo rodean por el Norte, urbanizándose así de forma adecuada este sector de abrupta pendiente natural. El complejo se compone de tres niveles superpuestos y simétricos, tanto al Este como al Oeste de edificio de espectáculos. El tránsito entre las tres plazas existentes a cada lado (Terrazas Inferior, Media y Superior) se efectúa mediante varias escalinatas, con la peculiaridad de que las escaleras situadas más cerca de la fachada del teatro presentan una planta curvilínea $(\text { gradus })^{31}$.

A pesar del estado incipiente en el que se encuentra la investigación, podemos asegurar algunos datos. En primer lugar, el extraordinario tamaño del edificio: 124,3 m de diámetro (420 pies). También peculiar resulta su diseño, por cuanto parece componerse de una cavea de forma ligeramente ultrasemicircular, según las huellas fosilizadas en el parcelario actual y - lo que resulta más fiable-, la simetría de las plazas aterrazadas que lo circundan desde el momento mismo de su edificación (fig. 3). Tamaño, configuración (ausencia de porticus post scaenam desarrollada) y decoración arquitectónica (claves de arcos decorados con máscaras), remiten a un modelo específico y claramente augusteo: el Teatro de Marcelo en Roma ${ }^{32}$. La forma de la $c a$ vea, si se confirmara su planta ultrasemicircular y apoyada en ladera, encuentra sin embargo mejores paralelos en edificios republicanos o helenísticos ${ }^{33}$. Tal vez podría proponerse como modelo el proyecto

\footnotetext{
${ }^{29} \mathrm{CIL} \mathrm{II}^{2} / 7, \mathrm{n}^{\circ} 231$.

${ }^{30}$ Los resultados de tales campañas de excavación y la interpretación de los restos como pertenecientes al teatro en Ventura, A., op. cit. n. 5, 153-168; Idem, art. cit. n. 10. El mismo informe, traducido al inglés, en: Ventura, A., León, P. y Márquez, C., art. cit. n. 5, 100-107.

31 Una escalinata similar, de planta cuvilínea y adosada a la fachada de la cavea, se documenta en el teatro de Tusculum, cuya construcción se fecha en la primera mitad del s. 1 a.C.: Dupré, X., Aquilué, X., et alii, Excavaciones arqueológicas en Tusculum. Informe de la campaña de 1996, Roma 1998, 36 y figs. 86-87.

32 Zanker, P., Augusto y el poder de las imágenes, Madrid 1992, 179-185.

${ }_{33}$ Como el ya citado teatro de Tusculum, supra n. 31, o el teatro de Teano: Mar, R., Vitrubio y la tipología de los teatros augusteos, El Braçal 10, 1994, 28 y fig. 2.
} 


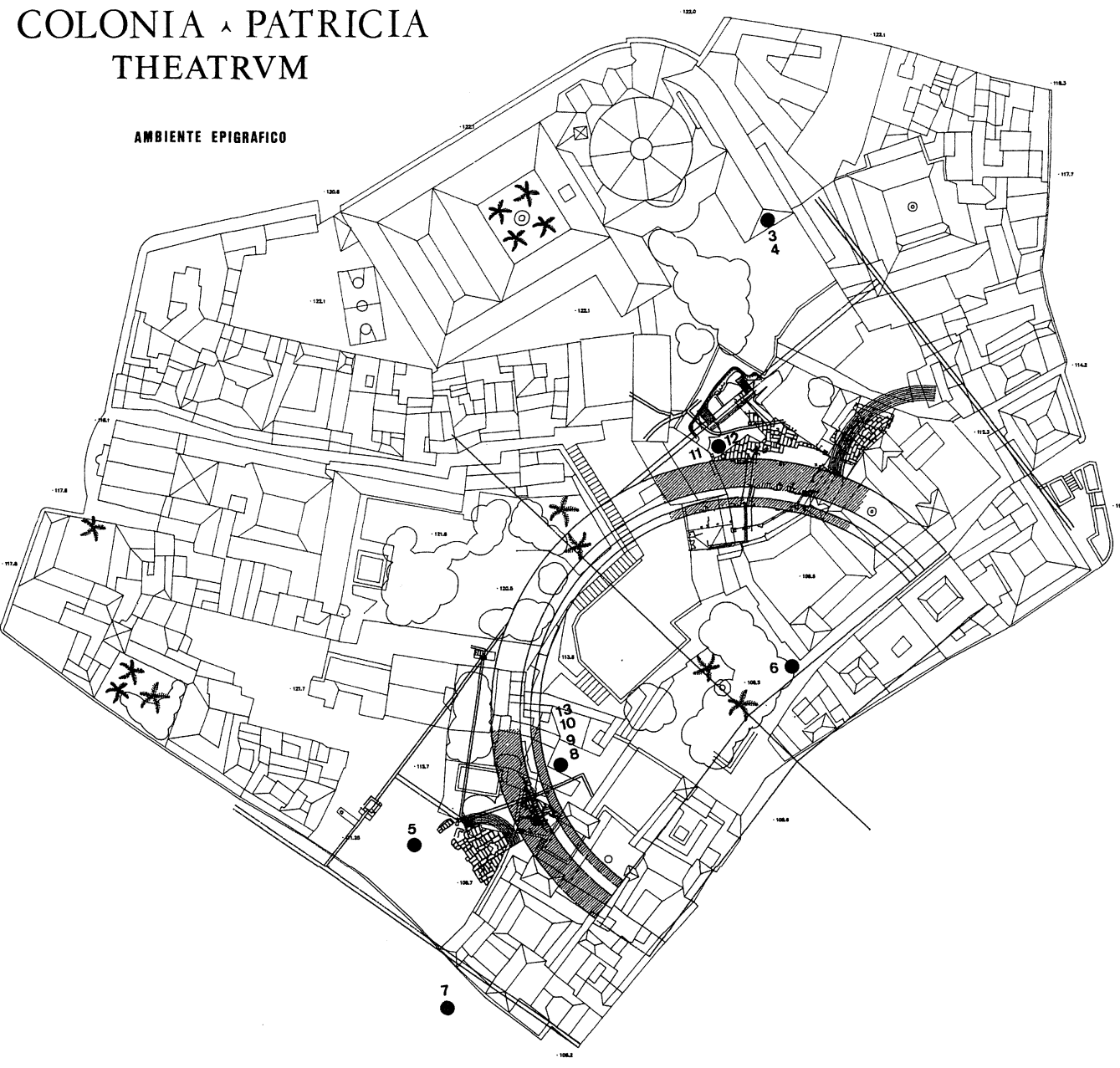

2

Fig. 3.-Plano del teatro, sobre parcelario actual, a escala 1:2000, con indicación de lugares de hallazgo de las inscripciones del catálogo.

cesariano de teatro adosado a la roca Tarpeya, nunca realizado, que habría unido la «nueva Roma» del Campo de Marte con el tradicional capitolio ${ }^{34}$. $\mathrm{Al}$ menos conceptualmente existe una similitud, por cuanto el complejo aterrazado a los lados del teatro patriciense sirve para suturar urbanísticamente la vieja Corduba con la nueva Colonia Patricia.

En cualquier caso, debe repararse en que tanto el peculiar modelo como el tamaño lo alejan de otros edificios hispanos construidos por evergetas locales

\footnotetext{
${ }^{34}$ La mención del proyecto cesariano: Suet., Caes. 44. La concepción del Campo de Marte en época augustea como una «nueva Roma» en Strab. Geog. V, 8. Vide los interesantes comentarios sobre el proyecto, del que el Teatro de Marcelo resultó ser sucesor, de Coarelli, F., Il Campo Marzio, Roma 1997, 586-589 y Gros, P., Architettura e società nell'Italia romana, Roma 1987, 126.
}

(v.g. Italica, Acinipo, Malaca). Si a esto añadimos que los teatros existentes en las otras dos capitales provinciales augusteas -Emerita y Carthago Nova ${ }^{35}$ - presentan un menor tamaño y fueron, no obstante, edificados por familiares directos del Princeps - por Agripa y por sus hijos Gayo y Lucio Césares, respectivamente-, no nos parece descabellado proponer una financiación imperial para el cordobés ${ }^{36}$.

35 Sobre la capitalidad de Carthago Nova en época augustea vide: Gimeno, J., Plinio Nat.Hist. III, 3, 21: reflexiones acerca de la capitalidad de Hispania Citerior», Latomus 53, 1994, 39-79.

${ }^{36}$ Los diámetros máximos, cronología y evergetas de los teatros mencionados: Emerita Augusta, 87 m., Agripa, año 15 a.C.; Alvarez Sáenz de Buruaga, J.M., Observaciones sobre el teatro romano de Mérida, El teatro en la Hispania ro- 


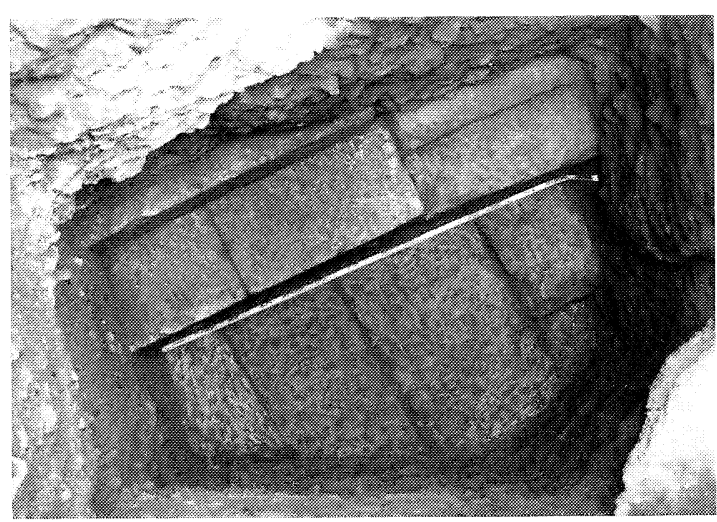

Fig. 4.-Corte 1, sondeo sur, campaña de excavación de 1999. Muro anular en opus quadratum de cimentación de la summa cavea; interfaz de saqueo de sillares del s. v d.C.

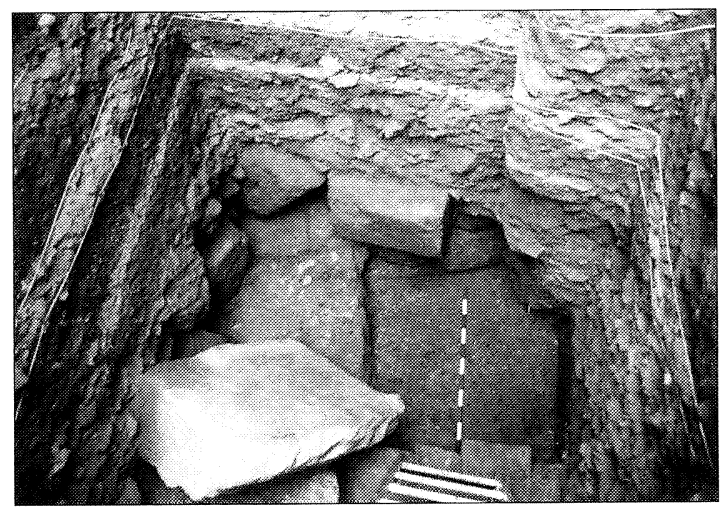

Fig. 5.-Corte 1, sondeo norte, campaña de excavación de 1999. Muros anulares en opus quadratum (arriba y abajo) y muro radial en opus caementicium (a la izquierda), de la cimentación de la summa cavea, saqueados durante el s. v d.C. Gran cornisa marmórea in loco.

mana, Badajoz 1982, 303 ss.. Carthago Nova, 87,6 m., Cayo y Lucio Césares, años 5-1 a.C.; Ramallo, S. y Ruiz, E., El teatro romano de Cartagena, Murcia 1998, 138-141. El enorme tamaño del teatro cordobés, $124.3 \mathrm{~m}$ de diámetro, nos hace sospechar una financiación imperial del mismo. Nos parece muy atractiva la hipótesis de relacionar el edificio con M. Claudio Marcello, sobrino, yerno y heredero de Augusto, tanto por las similitudes con el teatro que llevó su nombre en Roma, como por los lazos de patronato que sin duda debió mantener con la ciudad, heredados de su antepasado homónimo y Cos. 166,155 y 152 a.C., a quien se atribuye la fundación de Corduba: Strab. Geogr. 3,2,1. Respecto al establecimiento de lazos de patrocinium por parte de los fundadores de ciudades vide Harmand, L., Le patronat sur les colectivités publiques des origines au Bas-Empire, Paris 1958, 23-33. El tamaño del teatro cordobés sólo encuentra parangón con el teatro gaditano, $120 \mathrm{~m}$ de diámetro, cuya construcción se atribuye a $M$. Cornelio Balbo el Menor: Corzo, R., El teatro romano de Cádiz, Cuadernos de Arquitectura Romana 2, 1993, 133-140. También destaca por su diámetro, $106 \mathrm{~m}$, el teatro de Caesaraugusta, construido en época tiberiana: Beltrán Lloris, M., El teatro de Caesaraugusta. Estado actual de conocimiento, Cuadernos de Arquitectura Romana 2, 1993, 93-118.
En la actualidad, la investigación sobre el monumento se orienta hacia dos frentes principales. Por un lado, excavaciones en solares anejos propiedad del Museo Arqueológico, para conocer mejor la estructura interna de la cavea. La reciente campaña de 1999 nos ha permitido localizar nuevos tramos de su cimentación, desgraciadamente muy saqueada durante la Antigüedad Tardía y compuesta por tres potentes muros anulares en opus quadratum trabados entre sí por muros radiales (figs. 4 y 5). Pero también varios e interesantes elementos arquitectónicos in loco, como piezas de scalariae labradas en caliza micrítica gris (fig. 6) y de gradas en caliza marmórea blanca (figs. 7 y 8 ) ${ }^{37}$. Por otro lado, la

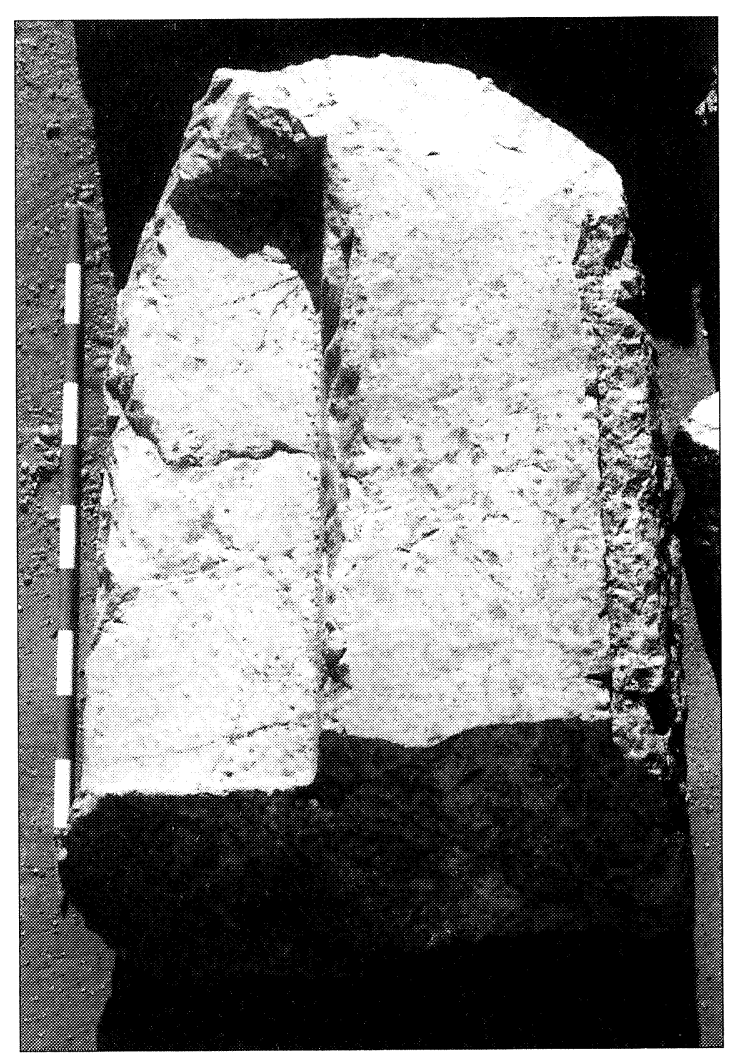

Fig. 6.-Pieza de scalaria recuperada en el corte 2 de la campaña de excavación de 1999.

${ }^{37}$ En el yacimiento se han localizado 5 fragmentos de las típicas piezas que conforman las scalariae en los edificios de espectáculos, con dos peldaños cada una. La más completa, fig. 6 , mide en total $100 \times 72 \times 40 \mathrm{~cm}$. Cada peldaño presenta un ancho de $90 \mathrm{~cm}$., una huella de $35-37 \mathrm{~cm}$ y un alzado de $15-18 \mathrm{~cm}$. Más abundantes son otras piezas de caliza marmórea blanca y sección en forma de triángulo rectángulo. En total, hemos contabilizado 37. Sus dimensiones son similares: $90 \mathrm{~cm}$ de anchura total, $90 \mathrm{~cm}$ mide la cara correspondiente a la hipotenusa, toscamente desbastada; $40 \mathrm{~cm}$ la cara del cateto menor, labrada «a gradina» y $70-75 \mathrm{~cm}$ la cara del 


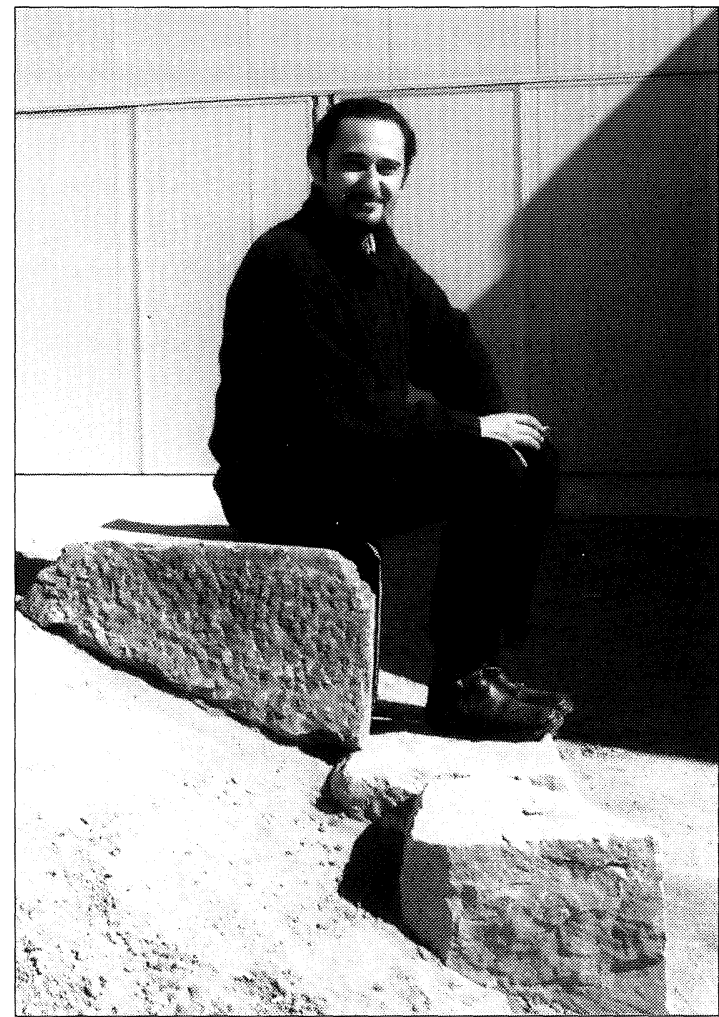

Fig. 7: Modelo experimental de colocación de las piezas marmóreas de sección triangular recuperadas en el yacimiento, que corresponderían a gradas con una «huella» de 70-75 $\mathrm{cm}$ y un alzado de $35-40 \mathrm{~cm}$.

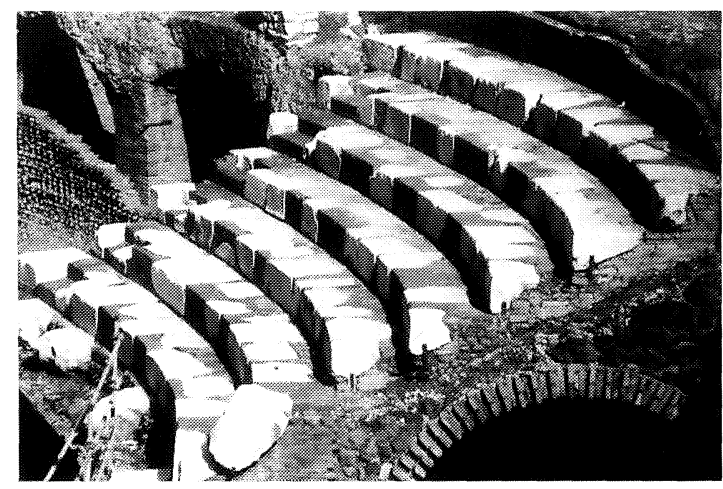

Fig. 8.-Paralelo de gradas similares a las cordobesas, dispuestas sobre bóvedas de opus caementicium: el Coliseo de Roma.

cateto mayor, pulimentada y desgastada por el uso. Esta última cara presenta un rebaje longitudinal en la arista del ángulo agudo, para encaje con otra pieza. Se trata de las gradas de la summa cavea, aquéllas dispuestas sobre bóvedas de opus caementicium, con paralelos muy ilustrativos en el $\mathrm{Co}-$ liseo de Roma: cfr. nuestras figs. 7 y 8 , como ensayo experimental de colocación. Un dibujo muy ilustrativo puede consultarse en Connolly, P., La ciudad antigua, Madrid 1998 , 197. catalogación y estudio de todos los restos arquitectónicos, escultóricos y epigráficos aparecidos casualmente en las inmediaciones del yacimiento, que ahora adquieren un mayor significado al conocerse el edificio concreto al que pertenecieron. Alentadores frutos ha brindado el estudio de la decoración arquitectónica emprendido por C. Márquez, pues confirma desde el punto de vista estilístico la cronología augustea del edificio, ya planteada a través del método estratigráfico ${ }^{38}$. Veremos cómo también el estudio del «ambiente epigráfico» permite concretar esta cronología y enriquecer nuestro conocimiento sobre el edificio y sobre la sociedad que lo construyó y empleó.

\section{ANÁLISIS DE LA EVIDENCIA EPIGRÁFI- CA: CATÁLOGO DE LAS INSCRIPCIONES HALLADAS EN EL ENTORNO DEL TEA- TRO (fig. 3)}

\section{CIL II, $2197=C I L I I^{2} / 7,253$ (fig. 9)}

Pedestal o ara cilíndrica de mármol, de fondo claro y abundantes vetas de colores verde y violeta, fracturado por la parte superior. Mide $101 \mathrm{~cm} \mathrm{de}$ altura conservada y $41-47 \mathrm{~cm}$ de diámetro. El imoscapo se resalta con un toro al que se superpone una escocia entre biseles. La inscripción se sitúa sobre un amplio «bucle» que forma el veteado, a modo de guirnalda. Las letras, capitales cuadradas de época augustea, miden $6 \mathrm{~cm}$ en lín. 1 ( $\mathrm{T}$ «longa», de $7 \mathrm{~cm}$ ) y $4 \mathrm{~cm}$ en lín. 2 . Se conserva en la actualidad en el Museo de Málaga. El texto dice:

\section{Augusto sacrum}

Desconocemos el lugar y circunstancias concretas del hallazgo, pero la primera noticia sobre la pieza, proporcionada por P. Díaz de Rivas en 1627, la sitúa en el Hospital de la Lámpara, actual c/ Amparo, junto a la Puerta de Pescadería, en la esquina suroriental del recinto amurallado de la Colonia $\mathrm{Pa}$ tricia. Su ubicación original en el «barrio de espectáculos» parece, pues, segura. Además, un testimonio de culto imperial tan precoz (en vida del Princeps) encaja mejor en el Teatro que en el también cercano Anfiteatro. La ubicación habitual de este tipo de arae cilíndricas en los teatros es la orchestra, como en los casos de Italica y Carthago

${ }^{38}$ Márquez, C., Modelos romanos en la arquitectura monumental de Colonia Patricia Corduba, AEspA 71, 1998, 124-133. 


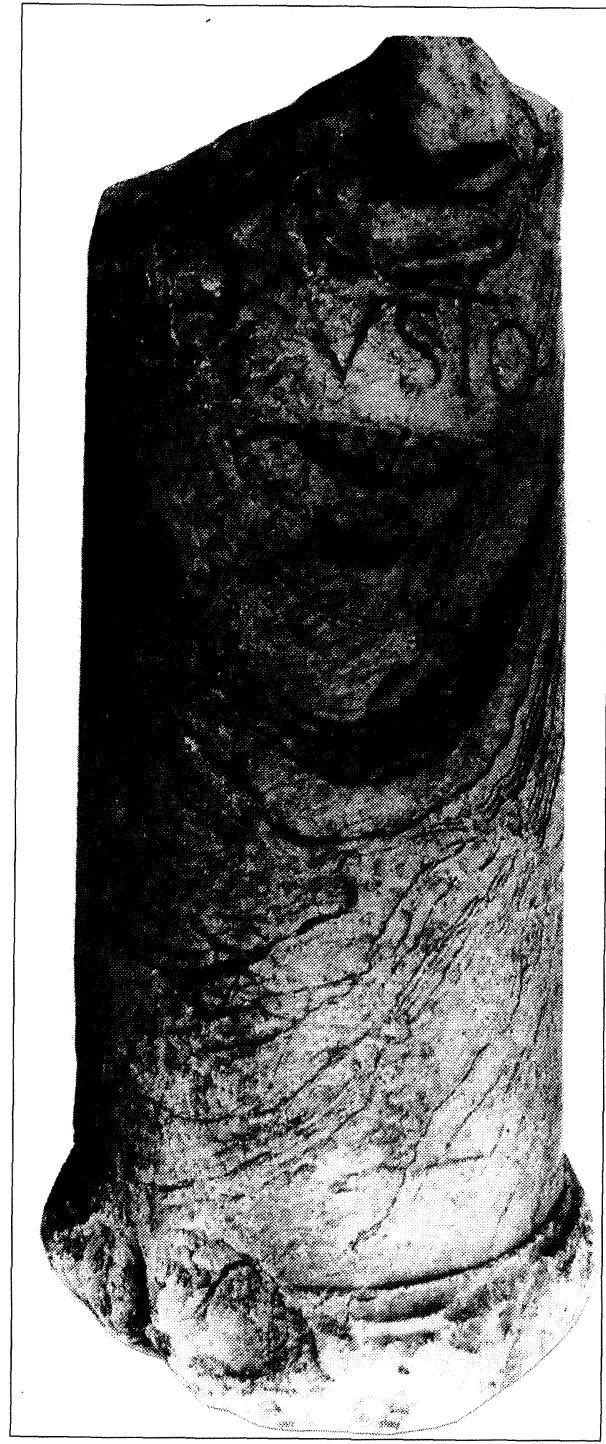

Fig. 9.- Inscripción n ${ }^{\circ} 1$ del Catálogo.

Nova ${ }^{39}$; si bien podría haber formado parte de un sacellum en el porticus post scaenam o en la ima cavea, como sucede en el teatro de Emerita ${ }^{40}$.

\section{CIL II, $2191=C I L I I^{2} / 7,225$}

Placa o paralelepípedo de piedra de dimensiones desconocidas. Desaparecida. La noticia de su ha-

\footnotetext{
${ }^{39}$ Corzo, R., Vivo Itálica. El Teatro, Granada 1994, 14-15. Ramallo, S., Ruiz, E., op. cit. n. 36, 143-150.

40 Trillmich, W., Un sacrarium de culto imperial en el teatro de Mérida, Anas 2-3, 1989-1990, 87-103 y láms. 8-13. Muy ilustrador el trabajo al respecto de Gros, P., Théâtre et Culte Impérial en Gaule Narbonnaise et dans la Péninsule Ibérique, Stadtbild und Ideologie, op. cit. n. 11, 381-390.
}

llazgo la proporciona Pérez Bayer en 1782: «en la calle de Sta. Clara», actual c/ Rey Heredia. El texto, bastante mutilado, dice:

\author{
Fortunae [---] \\ L(ucius) $\cdot$ Postumius $\cdot \mathrm{Bla}[---]$ \\ [p]oni-iussit-q[---] \\ [e?]ducandor[um?---] \\ [Kal(endis) O]ctobr(ibus) Pos[tumo et Capitone \\ cos.]
}

Stylow propone restituir en lín. 5 la datación consular del año 5 d.C. (C. Vibius Postumus y C. Ateius Capito), lo que proporcionaría un concreto terminus ante quem para la edificación del edificio de espectáculos cordobés. Un altar dedicado a la Fortuna Augusta se documenta en la orchestra del teatro de Carthago Nova ${ }^{41}$.

\section{CIL II, $2228 a-b=C I L I I^{2} / 7,298-299$}

«Dos trozos de piedra alabastrina de mucho peso y tamaño» hallados en 1761 al hacer los cimientos del nuevo colegio de Santa Victoria, actualmente desaparecidos. $\mathrm{n}^{\circ} 298$ :

$$
\begin{aligned}
& \text { [---]NA.SAC. } \\
& {[---]+O M A R \text {. }}
\end{aligned}
$$

Hübner consideraba posible que se mencionara en el texto a una sacerdos Romae.

$n^{\circ} 299$ :

$$
\begin{aligned}
& \text { [---]PROVI[---] } \\
& \text { [---]FIERI I[---] }
\end{aligned}
$$

Probablemente un pedestal de estatua votiva, ordenada colocar por el Concilium Provinciae o por uno de sus flamines.

\section{CIL II, $2219=C I L I I^{2} / 7,376$}

¿Pedestal? hallado en 1761 durante la construcción del colegio de Santa Victoria y actualmente desaparecida:
I.S.S.S.S.IATVA
ERVNT'EI.PI
$A \cdot F R \cdot E \cdot T E \cdot E$
A.DVMEN
AREM-IS

\footnotetext{
41 Ramallo, S., Inscripciones honoríficas del teatro de Carthago Nova, AEspA 65, 1992, 49-73.
} 
Stylow interpreta el texto corrupto como la dedicación («[posu]erunt», lín. 2) de una estatua (lín. 1) de bronce («aere» en lín. 3), cuyos costos fueron devueltos al dedicante por el homenajeado o uno de sus parientes («[impens]a remis[sa]» de lín. 5). Tanto esta pieza como las dos anteriores documentan un carácter público y representativo para la terraza superior oriental del complejo, tal vez relacionada con el culto imperial.

\section{Inédita (fig. 10)}

Pedestal o altar cilíndrico de piedra calcarenita, hallado en 1995 durante el seguimiento arqueológico de remociones de tierras en el solar de Casa Carbonell (promoción residencial «Altos de Santa Ana», con fachada a c/ Rey Heredia). Fracturado por la parte inferior, lo conservado mide $38 \mathrm{~cm}$ de altura y $46 \mathrm{~cm}$ de diámetro. Presenta bajo el cimacio un complejo juego de molduras de labra muy cuidada, con huellas de empleo del torno para su elaboración. De arriba abajo son: faja, cyma recta, media caña, baquetilla, rebajo, apófisis inversa y bisel. Se conservan restos de la $1^{a}$ línea de texto, con letras capitales cuadradas de $7 \mathrm{~cm}$ de altura, profundamente grabadas a bisel y con refuerzos poco desarrollados:

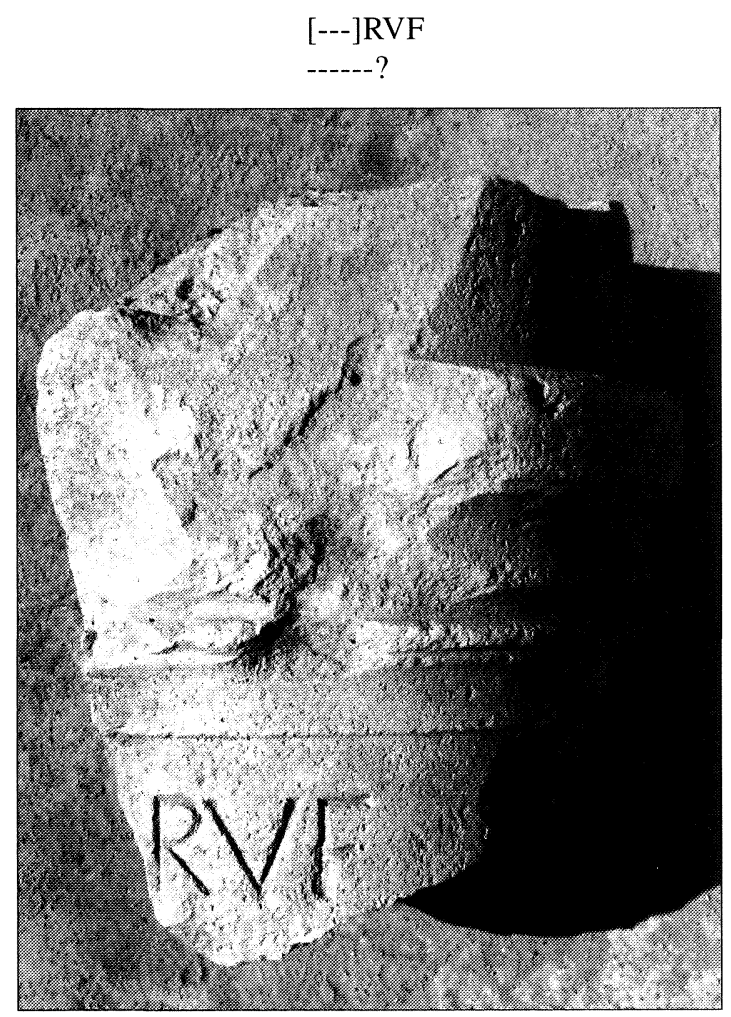

Fig. 10.--Inscripción nº 5 del Catálogo.

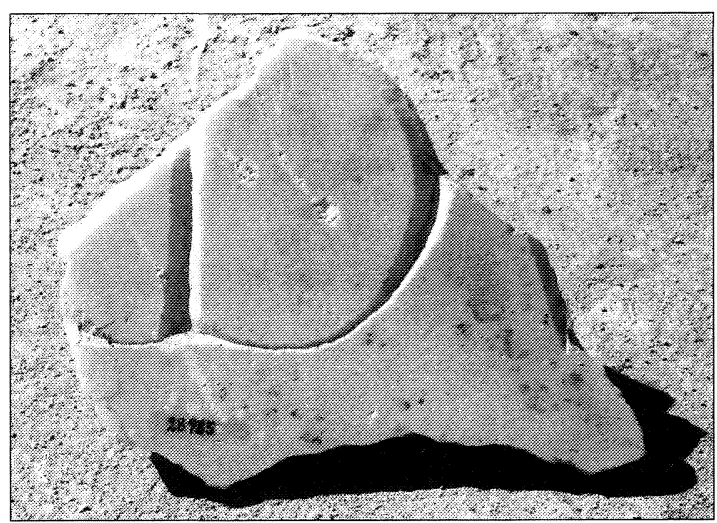

Fig. 11.-Inscripción n ${ }^{\circ} 6$ del Catálogo.

Por la paleografía y materia prima del soporte debe fecharse en época augustea. La ausencia de interpunciones impide un desarrollo del tipo $R(---)$ $v$ (otum) $f$ (ecit) o similar. Debe tratarse de una abreviatura, bien del cognomen Ruf(us), bien del topónimo Ruf(rae) (vicus Rufrae, en Campania). No aporta información respecto a la funcionalidad de la terraza inferior occidental aneja al teatro.

\section{CIL II $/ 7,615$ (fig. 11)}

Placa de mármol blanco fracturada por todos los lados de $14 \times 18 \times 1,5 \mathrm{~cm}$. Hallada en 1979 durante las labores de consolidación de los cimientos del palacio de los Páez Castillejo, en la esquina de la plaza de Jerónimo Páez con c/ Marqués del Villar. Litterae sunt optimae aetatis Augusti vel paululum recentiores, de $9,5 \mathrm{~cm}$ de altura:

$$
[--------\overline{D Y}[---]
$$

Se conserva en el Museo Arqueológico Provincial. Por el lugar de hallazgo, podría corresponder a una de las inscripciones fundacionales del Teatro, la situada sobre el dintel oriental del aditus maximus.

\section{CIL II, $2226=C I L I I^{2} / 7,311$ (fig. 12)}

Pedestal cilíndrico de caliza micrítica gris (piedra de mina). Hallado en el s. XVI «en casa de D. Fernando de la Cerda», se colocó en el Convento de la Encarnación, que se construía por entonces, en la esquina con la c/ Rey Heredia, donde actualmente se conserva. El lugar de hallazgo no debe distar mucho del de reutilización, atendiendo a las dimen- 


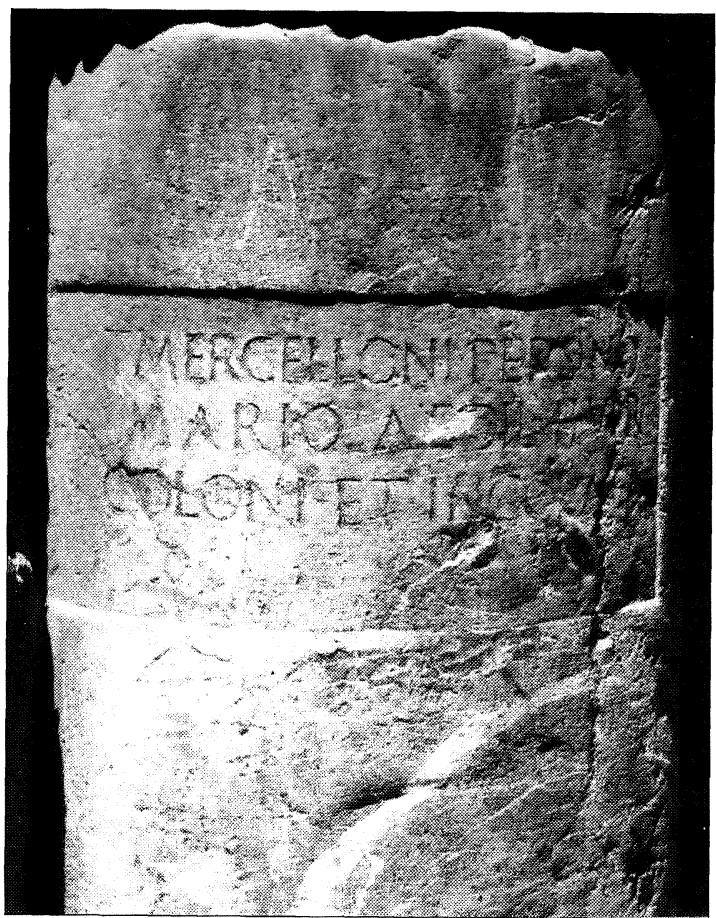

Fig. 12.- Inscripción $n^{\circ} 7$ del Catálogo.

siones de la pieza $(140 \mathrm{~cm}$ de altura y más de 200 $\mathrm{cm}$ de perímetro). T. Ramírez de Arellano ${ }^{42}$ narra un luctuoso suceso histórico, acaecido en 1586, en cuya trama participó un tal D. Andrés de la Cerda, posiblemente familiar directo de D. Fernando, cuya casa se situaba a muy poca distancia de la c/ Pedregosa (hoy c/ Blanco Belmonte). Es por eso que consideramos que su lugar de hallazgo está directamente relacionado con el complejo aterrazado occidental anejo al Teatro. La pieza presenta una cartela rectangular ligeramente rehundida de $27 \times$ $62 \mathrm{~cm}$, donde se encuentra el texto, inscrito en letras capitales cuadradas de época augustea y $4 \mathrm{~cm}$. de altura:

T(ito) Mercelloni.Persino

Mario·aedil(i)·Hvir(o)

Coloni-et.incolae

La superficie de la pieza ha sido levemente rebajada con bujarda en época contemporánea, habiendo perdido las letras su profundidad primigenia. El pedestal debió ubicarse originalmente en el complejo aterrazado occidental anejo al teatro, de carácter por tanto público y representativo.

42 Ramírez de Arellano, T., Paseos por Córdoba $6^{\mathrm{a}}$ ed., Córdoba 1985, 542, 544-545.

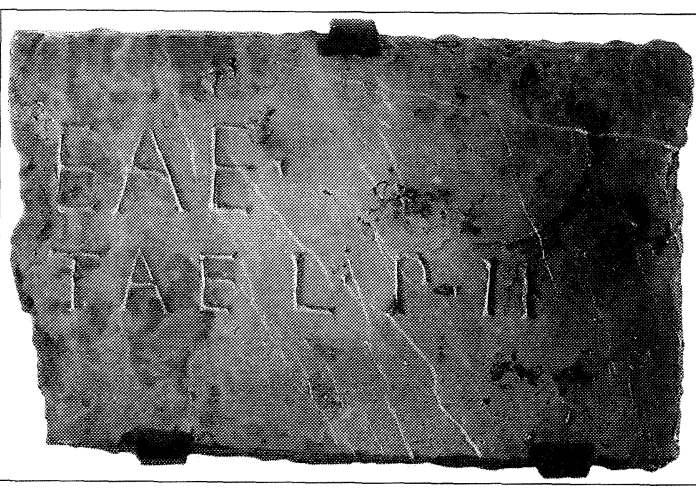

Fig. 13.-Inscripción $n^{\circ} 8$ del Catálogo.

\section{CIL II I7, 571 (fig. 13)}

Placa rectangular de piedra caliza micrítica gris (piedra de mina), fracturada por la izquierda, de 23 $\mathrm{cm}$ de altura, $37 \mathrm{~cm}$ de anchura y $7-4,5 \mathrm{~cm}$ de espesor. Fue hallada al realizar el sótano de la Casa Nahmias, en la Plaza de Jerónimo Páez y allí se conserva en un patio. Presenta la cara anterior alisada y las demás desbastadas, con ligera anathyrosis en los laterales, para facilitar su encaje en otra estructura. Las letras, capitales cuadradas, miden entre 3,2 y $5 \mathrm{~cm}$ de altura. La interpunción es de forma triangular con el vértice hacia abajo. Destaca la forma abierta de la letra $\mathrm{P}$, lo que, junto con la materia prima y apariencia general de la inscripción, remite a época augustea. El texto dice:

\section{[Anna]eae. \\ [Opta?]tae $\cdot 1$ (ocus) $\cdot \mathrm{p}($ edum $)$ II}

La morfología del soporte (placa y no cipo), la ausencia de fórmulas típicas, la indicación del nombre en genitivo y su hallazgo intramuros descartan la posibilidad de que se trate de una inscripción funeraria. Debe tratarse del chapado de un asiento en el teatro, localidad de $60 \mathrm{~cm}$ de anchura reservada a una mujer de la familia Annaea. La restitución del nomen es casi segura, pues este nombre es el más frecuente de entre los documentados en Hispania terminados en -ea ${ }^{43}$. No sucede lo mismo con el cognomen, restituido en nuestro caso a modo de ejemplo, pues varios de ellos de aparición frecuente podrían adaptarse a lo conservado.

${ }^{43}$ Alleicea, Peducea, Varaea, Callaea, Caldaea, Denea y Annaea: Abascal, J.M. Los nombres personales en las inscripciones latinas de Hispania. Murcia 1994, s.v. 


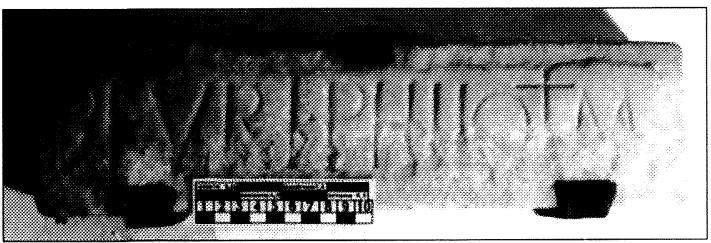

Fig. 14.-Inscripción nº 9-a del Catálogo.

\section{9. $C I L I I^{2} / 7,466$ a y $b$ (fig. 14)}

Paralelepípedo de mármol blanco labrado por todos sus frentes, de $10 \times 38 \times 8 \mathrm{~cm}$. La cara menor lateral derecha presenta un orificio, mientras que dos de las caras largas se encuentran inscritas. Hallado al construir el sótano de la casa Nahmias, en la Plaza de Jerónimo Páez; se conserva en uno de los patios del inmueble. La inscripción más antigua (cara a), con letras de $5 \mathrm{~cm}$. de altura (I longae de 6 $\mathrm{cm})$ e interpunciones triangulares con el vértice hacia arriba, dice:

\section{P(ubli)·FurI·PhilotImi}

Paleográficamente puede fecharse en la primera mitad del s. I d.C. En un momento posterior esta cara se retalló con acusada anathyrosis en el borde perimetral, afectando a la inscripción «a», al tiempo que, probablemente, se esculpió en la cara contigua el texto «b», con letras capitales de rasgos librarios, 5,3 - 3,3 cm de altura y fechables en la segunda mitad del s. I d.C.:

\section{Rullinae fil(iae)}

Quali monumento insertus fuerit talis lapis, non intellexi, escribe el editor del nuevo CIL. Es evidente que no se trata de inscripciones funerarias. $\mathrm{Al}$ estar los nombres en genitivo, deben constituir indicaciones de propiedad de localidades en el teatro, esta vez no inscritas en la placa de chapado de la grada, sino en piezas de subsellia.

\section{CIL $I I^{2} / 7,456$ (fig. 15)}

Paralelepípedo de piedra caliza azulada con vetas de color violeta (piedra de mina), fracturado por los lados derecho e izquierdo, de $9 \times 28,5 \times 7 \mathrm{~cm}$. Hallado en el mismo lugar y circunstancias que las dos inscripciones anteriores, se conserva también en la casa Nahmias. El texto, con letras librarias de 3,2 $\mathrm{cm}$ de altura, dice:

$$
[---] \text { Fannia.[---] }
$$

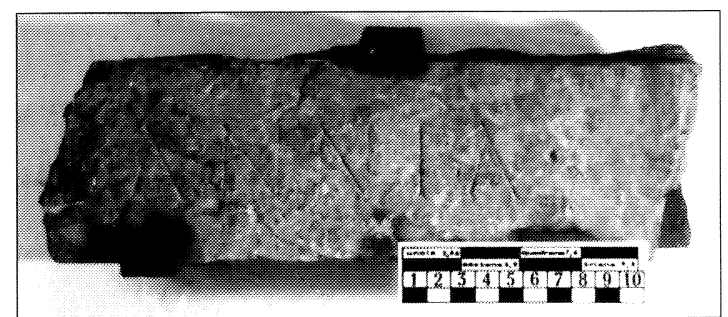

Fig. 15.-Inscripción $\mathrm{n}^{\circ} 10$ del Catálogo.

Stylow la fecha a finales del s. I d.C. A pesar de encontrarse el gentilicio en nominativo, debe tratarse de una reserva de asiento en el teatro, a juzgar por la morfología y dimensiones del soporte, similar a la inscripción anterior $\left(\mathrm{n}^{\circ} 9\right)$.

\section{1. $C I L I I^{2} / 7,608 a$ (fig. 16)}

Placa de piedra caliza gris (piedra de mina) fracturada por arriba y por la derecha, de $11 \times 19 \times 7,5$ $\mathrm{cm}$. La cara anterior alisada y las demás toscamente desbastadas. Apareció en superficie en el denominado «patio romano» del Museo Arqueológico, en 1993. El texto, con letras capitales cuadradas de 3,8 $\mathrm{cm}$ de altura, dice:

$$
\text { NVM[---] }
$$

Podría restituirse como un gentilicio en genitivo: Num(isiorum). Probablemente placa para chapado de asiento en el teatro, fechable desde el punto de vista paleográfico en época julioclaudia.

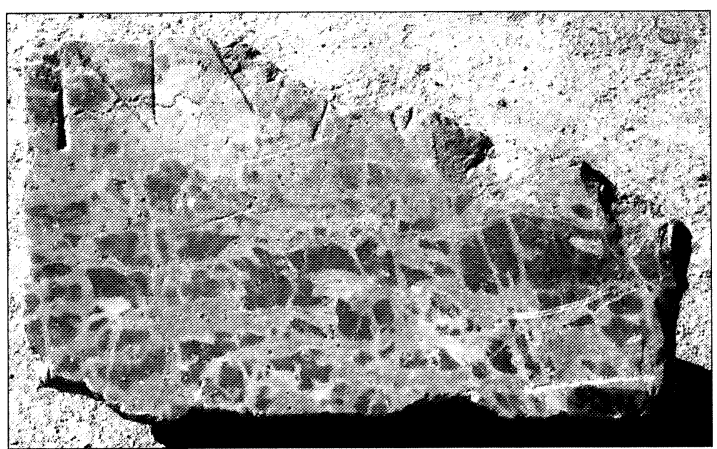

Fig. 16.-Inscripción n ${ }^{\circ} 11$ del Catálogo.

\section{Inédita (fig. 17)}

En el mismo lugar, durante la campaña de excavación de 1994, se localizaron una treintena de cornisas de doble frente labradas en piedra de mina, 


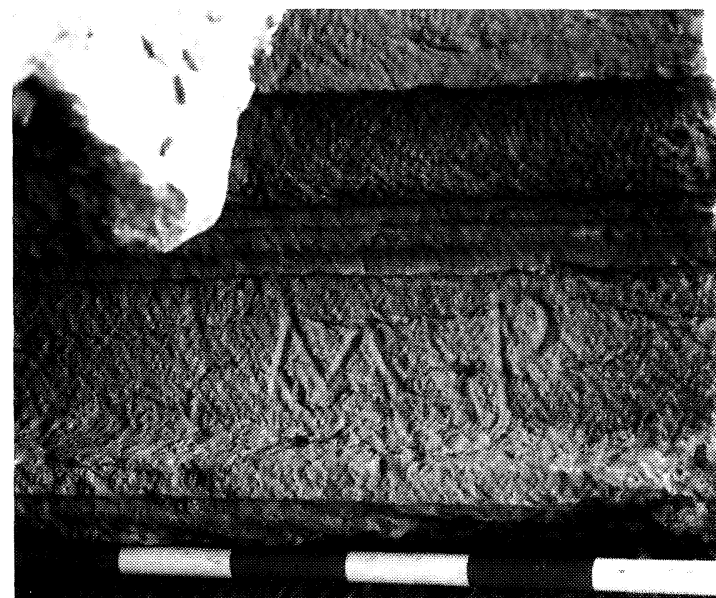

Fig. 17.-Inscripción nº 12 del Catálogo.

que originariamente decoraron la parte superior de la fachada del edificio de espectáculos. Dos de ellas muestran la misma inscripción en el friso, con letras capitales cuadradas de $9 \mathrm{~cm}$ de altura:

\section{$\mathrm{M} \cdot \mathrm{P}$}

Podrían interpretarse como las iniciales del artesano encargado de la elaboración de las cornisas ${ }^{44}$ o como marca de identificación del comitente que corrió con los gastos de su ejecución ${ }^{45}$. En cualquier caso, nos parece atractiva la hipótesis de restituir dichas iniciales como: M(ercellonis). $P($ ersini $)$ vel $M($ arii).P(ersini), apelando a la nomenclatura documentada en la inscripción $n^{\circ} 7$. Por la forma abierta del bucle de la letra $\mathrm{P}$ y la disposición de los trazos de la $\mathrm{M}$ (iguales en longitud y formando ángulos muy abiertos), debe fecharse en época augustea.

\section{El TEATRO: UN ESCENARIO PARA EL EVERGETISMO}

Correctamente ha definido Pilar León la Córdoba augustea como «UNA CIUDAD EN OBRAS», atendiendo a las numerosísimas construcciones que se emprendieron en estos momentos, con el teatro a la cabeza según acabamos de ver ${ }^{46}$. Cabe preguntarse entonces: ¿quiénes fueron los promotores de este auge edili-

\footnotetext{
${ }^{44}$ Marcas de cantero similares se documentan en elementos arquitectónicos del teatro de Cartagena: Ramallo, S., Ruiz, E. op. cit. n. 36, 90

${ }^{45}$ Algunas columnas del famoso pórtico del theatrum lapideum de Pompeyo en Roma portaban inscrito su nombre «Gnaei Pompei»- en la base : Gros, P., op. cit. n. 34, 124.

${ }^{46}$ León, P., Prólogo, Córdoba en tiempos de Séneca, op. cit. n. $16,12$.
}

cio, aparte del propio emperador? y ¿de dónde obtuvieron los recursos financieros para la adquisición de suelo, la producción e importación de los materiales constructivos empleados y la contratación de las maestranzas especializadas? Aunque todavía desconocemos bastantes datos como para responder de formanategórica a tales preguntas, sí contamos con indicios para comenzar, al menos, a comprender las causas de este evergetismo edilicio temprano ${ }^{47}$.

La primera necesidad básica para la praxis urbanística es la disponibilidad de suelo. En la Roma julioclaudia, los propios proyectos imperiales encontraban grandes dificultades para la adquisición del terreno necesario (ipiénsese en el incendio provocado por Nerón!). Una situación diferente, en tanto que más favorable, encontramos en nuestra ciudad, donde el terrible incendio del año 45 a.C. y las más de 22.000 bajas humanas producidas durante las guerras civiles habrían dado lugar a ingentes traspasos de propiedades en la vieja Corduba, posibilitándose así proyectos edilicios de amplio respiro. La expansión meridional augustea habría complementado esta oferta, proporcionando suelo residencial para la inversión privada de los colonos (construcción de sus casas) y el espacio necesario para la inserción de los grandes edificios de espectáculos, el teatro y el anfiteatro.

Segunda necesidad: los medios financieros. Aquí la respuesta se sustenta parcialmente en el mismo discurso. La guerra prolongada empobrece a los perdedores, pero genera grandes fortunas individuales en el bando ganador. En cualquier caso, es indudable la aceleración de los procesos de redistribución de riqueza, bien sea por defunciones, por requisamientos (botín de guerra) o proscripciones. Existen algunos testimonios concretos: los italicenses $\mathrm{Cal}$ purnio Salviano y Quinto Sestio, que participaron en el atentado contra el legado cesariano Casio Longino en Córdoba, salvaron la vida a cambio de 6 y 5 millones de sestercios, respectivamente ${ }^{48}$. Son sumas muy elevadas, suficientes para la construcción de un acueducto, por ejemplo ${ }^{49}$. En similar situación se encontraba otro personaje, L. Mercello ${ }^{50}$, de quien las fuentes literarias no reflejan su destino, pero que por las epigráficas sabemos dejó descendientes en nuestra ciudad homenajeados en el entorno inmediato del teatro (catálogo $\mathrm{n}^{\circ} 7$; vide infra).

47 Sobre el tema, en general, puede consultarse la obra de Melchor, E., El mecenazgo cívico en la Bética. Córdoba 1994.

${ }^{48}$ Bell. Alex. 55; Caballos, A., Itálica y los italicenses Sevilla 1994, 43-47.

49 Ventura, A., op. cit. n. 5, 62.

50 Bell. Alex. 52 y 53. 


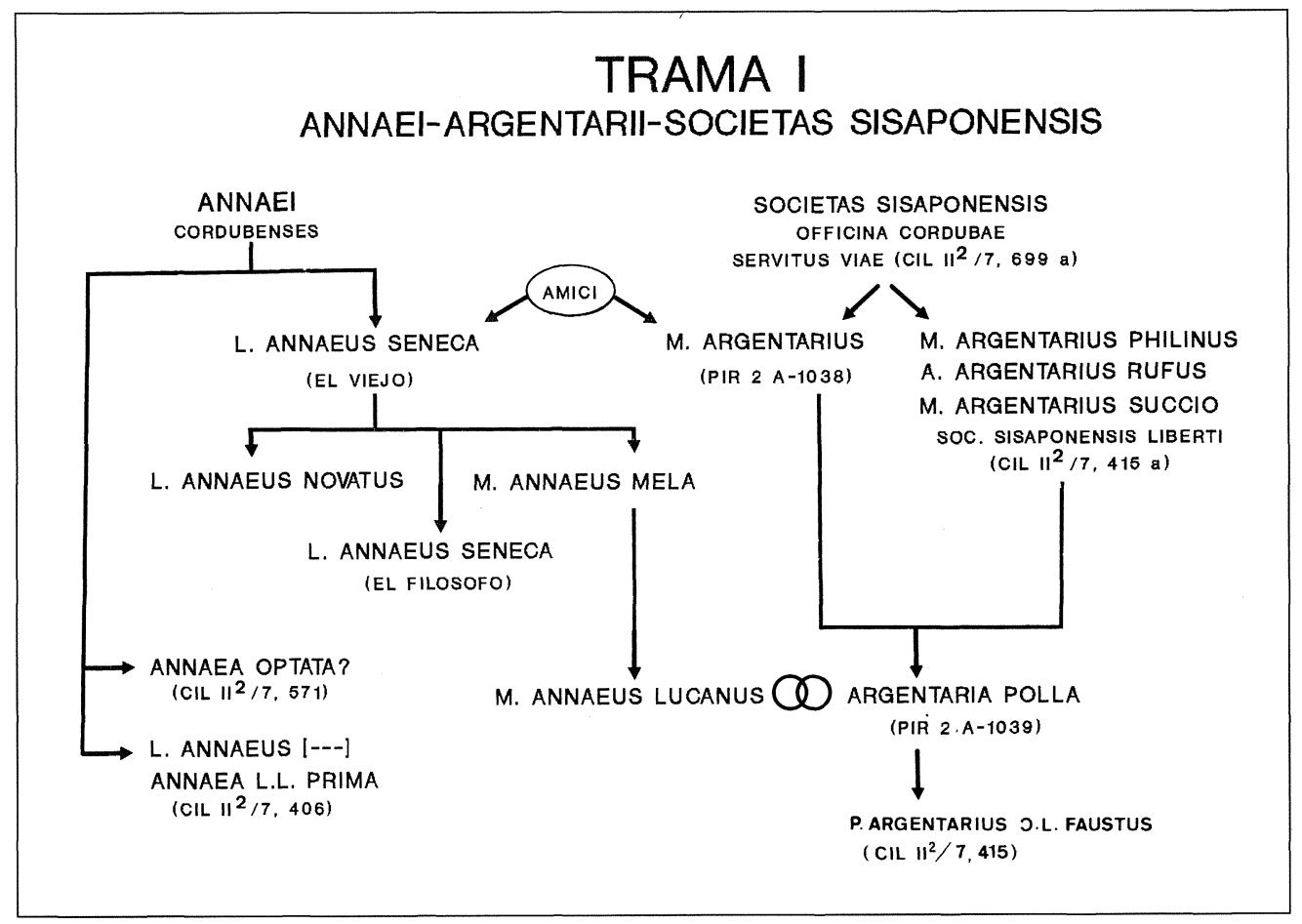

Fig. 18.-Cuadro de relaciones entre los Annaei, los Argentarii y la Societas Sisaponensis.

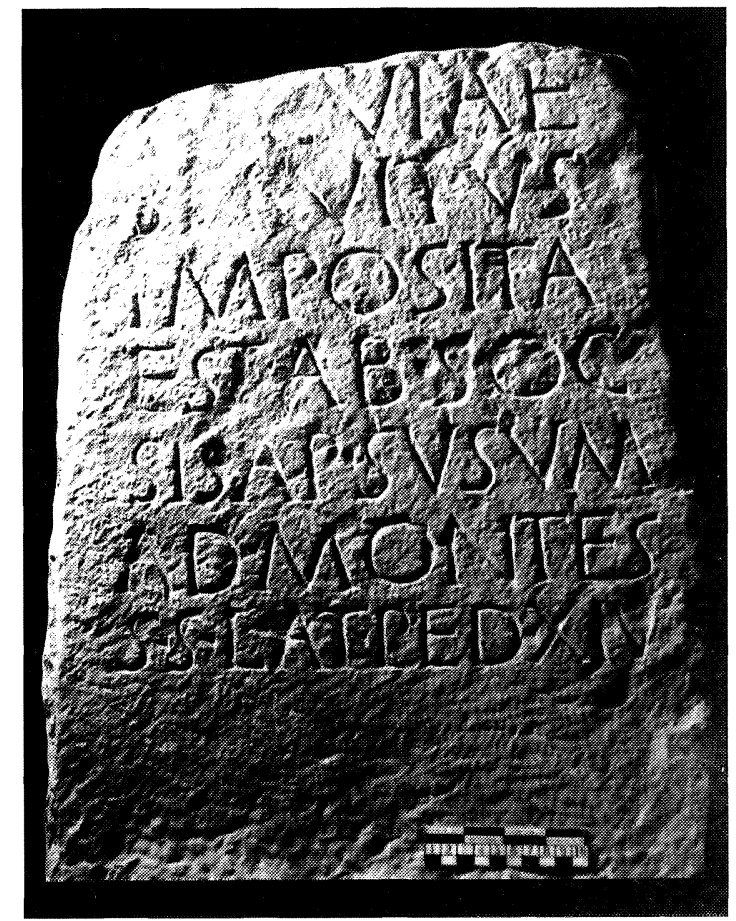

Fig. 19.--Inscripción CIL $\mathrm{II}^{2}$ /7, 699 a, hallada extramuros al norte de Corduba, que documenta la existencia de una servitus viae entre la ciudad y los Montes Societatis Sisaponensis.
Hemos de contar, además, con la acumulación de capital fruto de las productivas actividades mineras en la provincia a lo largo de toda la época republicana ${ }^{51}$. Es esta fuente de riqueza la que permitió el acceso al rango ecuestre y senatorial de las más destacadas familias cordobesas a comienzos de época imperial. En primer lugar los ANNAEI, emparentados con la GENS ARGENTARIA ${ }^{52}$ y vinculados, a través de ella, con la poderosísima SocIETAS SISAPONENSIS, explotadora de minas de plata en Sierra Morena ${ }^{53}$ pero, sobre todo, de las minas de cinabrio y mercu-

${ }^{51}$ Chic, G., Historia económica de la Bética en la época de Augusto. Sevilla 1997, 140-153.

${ }_{52}$ Dardaine, S., La gens Argentaria en Hispania, Melanges de la Casa de Velázquez 19, 1983, 5-15. Ventura, A., Inscripción funeraria, Córdoba en tiempos de Séneca, op. cit. n. 16, 216-217.

${ }_{53}$ La explotación de minas de plata en la Sierra Morena cordobesa por parte de la Societas Sisaponensis se puede rastrear a partir de los lugares de aparición de instrumentos, o resellos con las siglas S.S, como es el caso del famoso cubo de Posadas: Sandars, H.W., The Linares Bas-Relief and Roman mining operations in Baetica, Archaeologia LIX,2, 1905, 311-332. Domergue, C., Les mines de la Péninsule Ibérique dans l'Antiquité romaine. Roma 1990, 262. Otros yacimientos explotados por la societas en el marco de Sierra Morena se deducen de la existencia de contramarcas monetales con sus siglas - S.S - , sobre monedas de procedencia desconocida publicadas por García Bellido, M.P., Nuevos datos sobre minería y agricultura romanas en Hispania, AEspA 59, 1986, 19-21. 


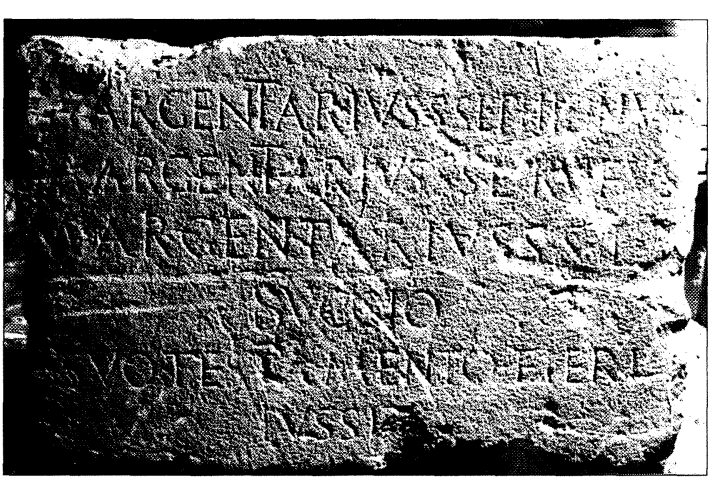

Fig. 20.--Inscripción CIL $\mathrm{II}^{2}$ /7, 415 a., hallada en el mismo lugar que la anterior, que documenta la adopción del gentilicio Argentarius por parte de los libertos de la Societas Sisaponensis.

rio de Almadén (Ciudad Real) en régimen de monopolio (figs. 18-20). La producción de cinabrio ha sido estimada en 53 toneladas anuales de mineral puro (vena), que una vez exportados a Roma vía Córdoba servían para elaborar 160.000 libras del preciado minio, colorante imprescindible para la pintura ${ }^{54}$. El mercurio resultante como subproducto también era considerado estratégico por sus aplicaciones para la obtención de oro por el procedimiento de amalgama y para el dorado del bronce ${ }^{55}$. No sorprende, por lo tanto, que libertos de la gens $\mathrm{Ar}$ gentaria ejerzan en Roma el oficio de banqueros, incluso en relación con el mercado del cobre ${ }^{56}$.

Otra familia ecuestre importante en estos momentos: los MERCELLONES-PERSINI emparentados, de

${ }^{54}$ Sobre la actividad de la Societas y la exportación de los minerales por ella explotados vía Corduba vide: Ventura, A. Susum ad montes S(ocietatis) S(isaponensis): Nueva inscripción tardorrepublicana de Corduba, Anales de Arqueología Cordobesa 4, 1993, 49-62. Muy interesante resulta la reseña a este trabajo realizada por Rodríguez Almeida, E., Una nova iscrizione ispanica relativa ai sociii miniarum Sisaponensium, BullCom XCVI, 1995, 173-178. Respecto a la Societas Sisaponensis, en general: Rodríguez Almeida, E., Producción y logística de algunos bienes: el caso de Roma, Actas del XIV Congreso Internacional de Arqueología Clásica vol. I, Tarragona 1994, 335-345.

55 Chic, G., Estrabón y la práctica de la amalgama en el marco de la minería sud-hispánica, La Bética en su problemática histórica. Ed. González Román, C.. Granada 1991, 7 29. Rodríguez Almeida, E., Alcune notule topografiche sul Quirinale di epoca domizianea, BullCom XCI.1, 1986, 4960.

56 CIL VI, 9186: «A(ulus) Argentari(us) A(uli) l(ibertus) Antioc(hus) a(rgentari) coactor inter aerarios..." Andreau, J., La vie financière dans le monde romain, Roma 1987, 165166. Opinamos que todos los individuos de gentilicio ARGENTARIUS, documentados en Hispania y Roma entre época tardorrepublicana y altoimperial, descienden, directa o indirectamente, de libertos de la Societas Sisaponensis. También resulta significativo, a propósito de la inscripción romana antes mencionada, la existencia en Córdoba de una Societas Aerariarum: CIL $\mathrm{II}^{2} / 7, \mathrm{n}^{\circ} 344$. un lado, con aquel L. Mercello italicense de época cesariana (fig. 21). De otro lado, con los PERSII ${ }^{57}$, constatados en la zona minera de Montoro y algunos de ellos dedicados también a la banca ${ }^{58}$. Pero más interesante aún resulta la polinomia de $T$. MERCELlo PERSINUS Marius (catálogo $\mathrm{n}^{\circ} 7$ ), edil $\mathrm{y}$ duumvir en Corduba y posteriormente, procurator Augusti ${ }^{59}$, pues demuestra, además de un contacto directo con el Princeps, un emparentamiento particularmente interesante con los MARII, propietarios casi absolutos de las minas de cobre y oro de Sierra Morena —de hecho, antonomásticos: Mons Marianum, Aes Marianum quod Cordubense, Mansio Mariana, Mons Mariorum ${ }^{60}$ - Varios Marii, libertos

57 La relación entre el $L$. MERCELLO de época cesariana y el T. Mercello Persinus Marius de época augustea se deduce del hecho de tratarse de los dos únicos casos de este gentilicio documentados en Hispania y ambos, precisamente, en Corduba: Abascal, J.M., op. cit. n. 43, s.v., p. 185. Probablemente se trate de padre e hijo. La relación entre los PERSII y los MERCELlones PERSINI se deduce de dos hechos. Por un lado, la raíz onomástica. En palabras de I. Kajanto: «the origin of the cognomina in -inus may also be sought in adoptions and in derivations from the gentilicia of the parents», The Latin Cognomina. Roma 1982, 36. Por otro lado, tanto el gentilicio Persius, como el cognomen derivado de él, Persinus, son muy infrecuentes en la epigrafía hispana: 4 y 3 casos, respectivamente, según Abascal, J.M., op. cit. n. 43, s.v. De estos 7 casos, 5 aparecen en inscripciones de Corduba o Epora. El gentilicio MERCELLO es extremadamente infrecuente, con apenas una decena de constataciones. Parece de origen etrusco y se documenta en Caere (CIL XI, 3613): Schulze, W., Geschichte Lateinische Eigennamen (1904), Berlin 1966, 301. Familiares directos de nuestros Mercellones cordobeses deben, por lo tanto, ser los documentados en Roma: T. Mercello Trebicus, su sierva Irene y su liberta Nepsis (CIL VI, 22410 y AE 1979, 34). Y también los documentados en Brindisi: T. Mercello y sus libertas Anthis y Festa (CIL IX, 10 y AE 1978, 147). Probablemente pertenezca a la familia, también, el T. Mercello Hilaro documentado en Ostia (CIL XIV, 1315).

$58 \mathrm{CIL} \mathrm{II}^{2} / 7, \mathrm{n}^{\circ} 152$ y 342

59 Hispania Epigraphica 2, Madrid 1990, no 345.

60 SeXto MarIo, el hombre más rico de Hispania, probablemente de rango ecuestre: Tac. Ann. 6,19,1. Respecto a sus minas de oro y cobre: Plin. Nat.Hist. 34,4. Topónimo Mansio Mariana derivado de su nombre: Itin. Anton. Wess. 444,3 y 445,3 . Tradicionalmente se supone que sus minas cordobesas se corresponden con las existentes en la localidad actual de Cerro Muriano. Dión Cassio LVIII, 22, cuenta una anécdota referida a Sexto Mario para argumentar su posición privilegiada en Roma, derivada de la amistad con Tiberio, ciertamente interesante. Estando en disputas con un vecino, cuyo nombre no se menciona, le invitó a su casa por dos días, durante los cuales ordenó que la villa de ese hombre fuera arrasada hasta los cimientos y vuelta a reconstruir con mayor tamaño y más lujosa. Cuando éste supo lo ocurrido y pidió explicaciones, Mario le respondió: «esto te muestra que poseo el conocimiento y el poder para repeler los ataques y también para recompensar la amabilidad». Pensamos que el vecino en cuestión bien pudiera ser Calpurnio Salviano, quien presentó en el año 25 una acusación contra Sexto Mario, siendo reprendida su actitud por Tiberio en persona y condenado por su osadía al exilio: Tac. Ann. 4, 36. Mario perdería el favor imperial y acabaría siendo ejecutado en el año 33 por 


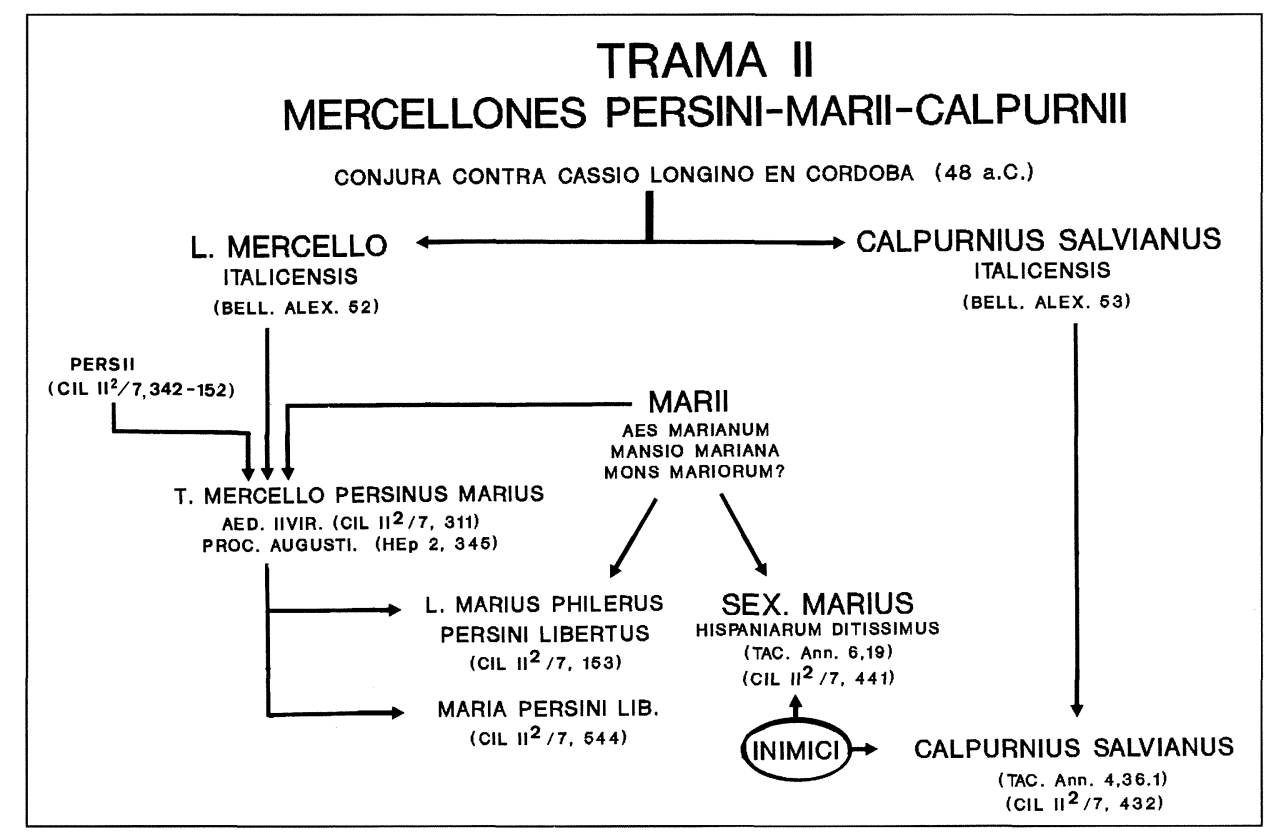

Fig. 21.-Cuadro de relaciones entre los Mercellones, Persii, Marii y Calpurnii.

de Persini, se documentan en Corduba y, de nuevo, en la zona minera de Epora (Montoro) ${ }^{61}$. La presen-

orden de Tiberio, que confiscó sus minas: Tac. Ann. 6,19; Suet. Tib. 49. Éstas pasaron a ser administradas por procuratores Montis Mariani: CIL II, 1178. Otro problema interesante es el referido al topónimo MANSIO MONS MARIORUM, mencionado por el Itin. Ant. 432.4, que se localiza en la vía Itálica-Emérita, en los alrededores de la actual localidad de Almadén de la Plata. Algunos autores propusieron corregir dicho topónimo por MONS MARMORUM, apelando tanto a la existencia de importantes canteras de mármol blanco en la zona, como al hecho de no conocerse vínculos entre Sexto Mario e Itálica: González, J., Mansio Mons Mariorum, Habis 27, 1996, 90-91 y n. 15. Ahora bien, según el cuadro de nuestra fig. 21 , sí que existe un vínculo, indirecto pero por partida doble. El Calpurnio Salviano que acusa a Mario debe ser nieto del individuo homónimo, italicense, involucrado en la conjura contra Casio Longino realizada en Corduba el año 48 a.C., en la que participa también otro italicense, L. Mercello, cuyo hijo está emparentado ya en época augustea con los Marii. Es más, si aceptamos que los yacimientos mineros enclavados en los alrededores de Almadén de la Plata pertenecieron a los Marii, tendríamos un argumento más para plantear la propiedad imperial de las famosas canteras de mármol, a partir de la confiscación tiberiana. Sobre el tema vide: Cisneros, M., Mármoles de importación y mármoles de sustitución: su utilización en algunas ciudades hispanas, Veleia 14, 1997, 197-198; Rodá, I., Los mármoles de Itálica. Su comercio y origen, Italica MMCC, Sevilla 1977, 172-174.

${ }_{61} \mathrm{CIL} \mathrm{II}^{2} / 7, \mathrm{n}^{\circ} 153$ y 544 . La presencia en la nomenclatura de T. MerCello Persinus Marius de un gentilicio en la posición final, como segundo cognomen (Marius), podría explicarse de dos formas diferentes. Una, improbable, que ese gentilicio fuese materno. La segunda, a nuestro juicio más probable, que se esconda tras él una adopción. Tendríamos así un personaje de nombre (-).MARIUS PERSINUS, adoptado por un T. MERCELLO, generándose una onomástica del tipo: praenomen adoptivo + nomen adoptivo + cognomen original cia de varias «marcas de cantero» en las cornisas del teatro, elaboradas en caliza micrítica local de Sierra Morena («piedra de mina»), con las siglas M.P (catálogo $\mathrm{n}^{\circ} 12$ ), tal vez signifiquen la participación de esta familia en la ornamentación del edificio, o bien su propiedad respecto a las canteras ${ }^{62}$.

Estas importantes familias (y otras menos conocidas literariamente, como los Numisii, los Furii, los Postumii) se constatan epigráficamente en el teatro: el edificio se concibe así, desde el principio, como escenario para el culto al emperador (catálogo $n^{\text {os }} 1-2$ ) y para la autorrepresentación de las élites locales, enriquecidas a su amparo.

+ nomen original, analizadas por Salomies, O. Adoptive and Polyonymous Nomenclature in the Roman Empire, Comm. Hum. Lit. 97, Helsinki 1992, 24-25. De esta manera se explica mejor la existencia de un L. MARIUS PERSINI L(IBERTUS) PHILEROS: CIL II ${ }^{2} / 7, \mathrm{n}^{\circ} 153$

${ }_{62}$ Los afloramientos de la piedra caliza micrítica gris, denominada comúnmente en Córdoba «piedra de mina», se ubican en la formación geológica Linares-Pedroche del Cámbrico cordobés, en varios puntos de la sierra más cercana a la ciudad, fundamentalmente hacia el Noreste. El empleo a escala regional de este tipo de piedra para la elaboración de elementos arquitectónicos y soportes epigráficos comienza en época tardorrepublicana, como manifiesta la famosa inscripción de La Rambla del año 49 a.C., que conmemora la construcción de una porta: $A E 1986, \mathrm{n}^{\circ} 369$. La misma piedra se emplea profusamente en los principales monumentos de la Córdoba augustea, como el foro o el teatro. Una cornisa del teatro muestra, en la cara más toscamente desbastada, la inscripción numérica CLVII, similar a la que se documenta en bloques de canteras marmóreas famosas, como las proconesias. De tales datos se deduce una explotación a gran escala y perfectamente organizada de este recurso lapídeo. 